NBER WORKING PAPER SERIES

\title{
MORAL COSTS AND RATIONAL CHOICE: THEORY AND EXPERIMENTAL EVIDENCE
}

\author{
James C. Cox \\ John A. List \\ Michael Price \\ Vjollca Sadiraj \\ Anya Samek \\ Working Paper 22234 \\ http://www.nber.org/papers/w22234
}

\author{
NATIONAL BUREAU OF ECONOMIC RESEARCH \\ 1050 Massachusetts Avenue \\ Cambridge, MA 02138 \\ May 2016
}

We thank the John Templeton Foundation for funding this research under the Science of Philanthropy Initiative. We thank Justin Holz, Andrew Christensen, and Kristin Troutman for excellent research assistance. We thank participants at the Economic Science Association conferences in Sydney and Dallas, American Economic Association conference (especially our discussant Bill Harbaugh), seminar and workshop participants at the University of Pittsburgh, Duke University, Georgia State University, University of Technology Sydney, Queens University of Technology, Monash University and Virginia Commonwealth University for helpful comments. The views expressed herein are those of the authors and do not necessarily reflect the views of the National Bureau of Economic Research.

NBER working papers are circulated for discussion and comment purposes. They have not been peer-reviewed or been subject to the review by the NBER Board of Directors that accompanies official NBER publications.

(C) 2016 by James C. Cox, John A. List, Michael Price, Vjollca Sadiraj, and Anya Samek. All rights reserved. Short sections of text, not to exceed two paragraphs, may be quoted without explicit permission provided that full credit, including $\odot$ notice, is given to the source. 
Moral Costs and Rational Choice: Theory and Experimental Evidence

James C. Cox, John A. List, Michael Price, Vjollca Sadiraj, and Anya Samek

NBER Working Paper No. 22234

May 2016

JEL No. C9,C93,D01,D03

\begin{abstract}
$\underline{\text { ABSTRACT }}$
The literature exploring other regarding behavior sheds important light on interesting social phenomena, yet less attention has been given to how the received results speak to foundational assumptions within economics. Our study synthesizes the empirical evidence, showing that recent work challenges convex preference theory but is largely consistent with rational choice theory. Guided by this understanding, we design a new, more demanding test of a central tenet of economics - the contraction axiom-within a sharing framework. Making use of more than 325 dictators participating in a series of allocation games, we show that sharing choices violate the contraction axiom. We advance a new theory that augments standard models with moral reference points to explain our experimental data. Our theory also organizes the broader sharing patterns in the received literature.

James C. Cox

Experimental Economics Center

Andrew Young School of Policy Studies

Georgia State University

P.O. Box 3992

Atlanta, GA 30302-3992

jccox@gsu.edu

John A. List

Department of Economics

University of Chicago

1126 East 59th

Chicago, IL 60637

and NBER

jlist@uchicago.edu

Michael Price

Experimental Economics Center

Andrew Young School of Policy Studies

Georgia State University

P.O. Box 3992

Atlanta, GA 30302-3992

and NBER

mprice25@gsu.edu

Vjollca Sadiraj

Experimental Economics Center

Andrew Young School of Policy Studies

Georgia State University

P.O. Box 3992

Atlanta, GA 30302-3992

vsadiraj@gsu.edu

Anya Samek

Center for Economic and Social Research

University of Southern California

635 Downey Way

Los Angeles, CA 90089

anyasamek@gmail.com
\end{abstract}




\section{Introduction}

One of the most influential bodies of economics research in the past two decades revolves around whether and to what extent people value efficiency, fairness, equity, and reciprocity. Experimental work has provided evidence that such motivations can be important in creating and determining surplus allocations in markets (see, e.g., Fehr et al., 1993; Landry et al., 2010), with accompanying theoretical models of social preferences providing a framework to rationalize such behaviors (see, e.g., Rabin, 1993; Charness and Rabin, 2002; Dufwenberg and Kirchsteiger, 2004; Fehr and Schmidt, 1999; Bolton and Ockenfels, 2000; Andreoni and Miller, 2002; and Cox et al., 2008).

Within this line of research, there is a class of experiments that is used to measure pro-social preferences, with typical experiments taking the form of gift exchange games, public goods games, ultimatum games, trust games, and dictator games. While such games have shown that social preferences touch many areas of economic interactions, what is largely missing is a deeper understanding of whether individual choices violate deeply held economic tenets. At this point, it is too early to conclude definitively, but the received literature suggests that sharing behaviors observed are consonant with neoclassical theory. For instance, in a seminal study, Andreoni and Miller (1993) show that in a modified dictator game subjects choices satisfy the key axiom of revealed preference. ${ }^{1}$ More recently, Andersen et al. (2011) provide data that reveals demand curves for fairness in an ultimatum game are downward sloping. While in its infancy, this work suggests that certain sharing behaviors can be captured by the standard economic model.

The shortage of work testing basic tenets in the sharing literature contrasts sharply with other areas of behavioral economics, which have lent deep insights into foundational assumptions within economics. For example, for riskless choice, received results reveal that many consumers have preferences defined over changes in consumption, but individual behavior converges to the neoclassical prediction as trading experience intensifies (see, e.g., Kahneman et al., 1990; List, 2004; Engelmann and Hollard, 2010).

Relatedly, for choice that involves risk, several scholars (see, e.g., Harless, 1992; Hey, 1995; and Hey and Orme, 1994) present econometric estimates of indifference

\footnotetext{
${ }^{1}$ Fisman et al. (2007) extend this earlier work by developing an experimental framework that allows the researcher to not only test the consistency of choices but also recover individual level preferences for giving. Fisman et al. (2015) explore how preferences for giving are impacted by macroeconomic shocks.
} 
curves under risk at the individual level that show neither expected utility theory nor the non-expected utility alternatives do a satisfactory job of organizing behavior. Choi et al. (2007) extend this analysis by developing an experimental protocol that allows the researcher to both test the consistency of choices with the assumption of utility maximization and estimate a two-parameter utility function for each individual. Of course, these examples are not exhaustive, as there are many other active research inquiries in this spirit, including those exploring intertemporal choice (see, e.g., Laibson, 1997; O’Donoghue and Rabin, 1999, 2001; Frederick et al., 2002), asymmetry and transitivity of preferences (Tversky, 1969; Slovic 1995; Cox and Grether, 1996; List, 2002), and conditional altruism (Dufwenberg and Kirchsteiger, 2004; Cox et al., 2008).

Our study follows the spirit of this broader literature by exploring whether basic economic tenets are satisfied in sharing choices as observed in the dictator game, which has emerged as a workhorse in the social science literature. Recently, in an effort to better understand the factors that motivate sharing, a number of scholars have augmented the standard dictator game by varying the feasible action set (e.g., List, 2007; Bardsley, 2008; Cappelen, et al., 2013). Amongst other results, these studies report that dictators change their allocations in interesting ways when presented a chance to take as well as to give to others. For example, in the typical dictator game the experiment is framed such that "giving nothing" is the least generous act, and substantial sums of money are given away (Engel, 2011). Yet, if subjects are allowed to give or take money from the other player, subjects give much less to the other player on average.

The first goal of our study is to step back from the burgeoning literature and attempt to synthesize what we have learned theoretically from these experimental exercises. We explain that the traditional dictator game, wherein more than 60 percent of dictators pass a positive amount of money, is consistent with neoclassical convex preference theory (Hicks, 1946; Samuelson, 1947). Yet, more recent results from this literature (e.g., List, 2007; Bardsley, 2008; Cappelen, et al., 2013) provide evidence that challenges convex preference theory. Nevertheless, these new data are largely consistent with rational choice theory (Sen, 1971).

Our second goal is to build on the experimental literature by conducting a dictator game experiment that generates a stark test of a foundational assumption within economics: the contraction axiom. For singleton choice sets, the contraction axiom is the necessary and sufficient condition for a choice function to be rationalizable by a weak 
order (Sen, 1971). ${ }^{2}$ To test whether this central theoretical condition holds, we present a novel experiment with 329 children ages 3-7 who participated in a series of dictator games in which we systematically varied the feasible set and the actions available to the dictator. ${ }^{3}$ Designing an experiment that preserves the opportunity set but allows dictator giving or taking provides one type of test for violations of the contraction axiom. This important design departure from the List (2007) and Bardsley (2008) studies makes it possible for us to explore rational choice theory at a deeper level. Furthermore, by preserving the initial endowment but varying the feasible set, we depart from recent literature on effects of social norms on play in dictator games (Krupka and Weber, 2013; Kimbrough and Vostroknutov, 2015). Unlike their designs, ours allows discrimination between the effects on choices of initial endowments and other salient features of feasible sets.

Our experimental data yields several insights. First, we find that our children subjects exhibit patterns of giving and taking behavior very similar to university students (List, 2007; Bardsley, 2008; Korenok et al., 2014) and a representative sample of Danish adults (Cappelen, et al., 2013). In particular, contracting the feasible set to remove taking options causes both children and student subjects to provide higher payoffs to recipients and keep less for themselves. Second, and most importantly, in our experiment such contraction causes subjects to keep more for themselves even when the contracted set contains the originally-chosen allocation, which is inconsistent with the contraction axiom and therefore at odds with extant rational choice theory. Crucially, combined with previous results, our data suggest how rational choice theory can be extended to explain the overall behavioral patterns.

This understanding leads to our third goal of the study - to develop an axiomatic foundation for other-regarding behavior that accounts for such factors and test its empirical validity with data from both our own experiment and previous work. ${ }^{4}$ Our theoretical development follows the approach in Cox and Sadiraj (2010) to extend choice theory to accommodate dictator game data that violates a central tenet of conventional theory - in this case, the contraction axiom (e.g., Sen, 1971). The key component of our

\footnotetext{
${ }^{2}$ For set-valued choice functions, rationality is equivalent to Sen's (1971) properties $\alpha$ and $\beta$ (see below). Property $\alpha$ is the contraction axiom.

${ }^{3}$ In this paper, we have elected to use "action set" to refer to actions of taking or giving whereas "opportunity set" denotes the conventional set of feasible allocations, i.e., it is ordered pairs of dictator's and recipient's payoffs.

4 See also experiments by Grossman and Eckel, 2015, Engel, 2011; Korenok et al., 2013; Korenok et al., 2014; Zhang and Ortmann, 2014.
} 
theory is the identification of moral reference points that are features of the environments, i.e., feasible sets and initial endowments. While moral cost models have been suggested in previous work (e.g., Levitt and List, 2007; DellaVigna et al., 2012; Kessler and Leider, 2012; Ferraro and Price, 2013; Krupka and Weber, 2013; Kimbrough and Vostroknutov, 2015), such models have been based upon direct assumptions regarding the form of utility functions (requiring strong regularity conditions on preferences that are not essential to choice rationality), and do not reconcile the key finding that our data are at odds with rational choice theory. Importantly, we also show that our model is consistent with data reported in Korenok et al. (2014); even data that are at odds with their model.

We view our study as fitting in nicely with the "theory speaking to experiment and experiment speaking to theory" research culture that has permeated experimental economics for decades. While modern economies rely on sharing relationships, how such sharing patterns match the foundational assumptions of economics remains illunderstood. Beyond providing theoretical direction, our data highlight that young children's choices vary with moral reference points, leading us to conclude that such motivations are innate, or formed early in life. In this regard, beyond speaking to theorists, our work contributes to a growing body of literature investigating the economic decisions made by young children as a means to explore the developmental roots of social preferences (e.g., Harbaugh et al., 2003; Benenson et al., 2007; Fehr et al., 2008; List and Samek, 2013). Yet, our experiment extends this literature in a new direction in that we explore the importance of moral reference points on the choices of young children.

The remainder of our paper is structured as follows. Section 2 presents the design of our experiment and the procedures we used to conduct it with young children. Section 3 discusses the implications of extant theory and develops our axiomatic theory incorporating moral reference points. Section 4 presents our experimental results. Section 5 presents implications of our theory for related experiments. Section 6 concludes.

\section{Background, Design, and Protocol}

The first dictator game experiment in economics is Kahneman et al. (1986), who gave subjects a hypothetical choice of choosing an even split of $\$ 20$ (\$10 each) with an 
anonymous subject or an uneven split $(\$ 18, \$ 2)$, favoring themselves. Three-quarters of the subjects opted for the equal split. The wheels were set in motion for three decades of research examining sharing and allocation of surplus in the lab and field. One stylized result that has emerged from the voluminous literature is that more than 60 percent of subjects pass a positive amount to their anonymous partners, and conditional on a positive transfer, roughly 20 percent of the endowment is passed.

Even though some scholars have argued that such giving patterns violate deeply held economic doctrines, it is important to recall that preference order axioms do not uniquely identify the commodity bundles. In a two-commodity case, my preferences may be defined over my hotdogs and my hamburgers. But the same formal theory of preferences can be applied to two commodities identified as my hamburgers and your hamburgers. Identification of the commodities in a bundle is an interpretation of the theory. In this way, neoclassical preference theory (Hicks, 1946; Samuelson, 1947) can be used for agents who are either self-regarding or other-regarding. As such, strictly speaking, the received results of generous sharing in standard dictator games do not represent a rejection of neoclassical preference theory. Rather, they represent a rejection of a joint hypothesis: neoclassical preferences and the assumption that preferences are self-regarding.

More recently, List (2007) and Bardsley (2008), amongst others, have used laboratory dictator game experiments to explore how choices are influenced by introducing opportunities to take. This line of work presents a challenge for convex preference theory, as we explain. We use this literature as our starting point, and design treatments that pose a more fundamental challenge to choice rationality than heretofore explored.

\subsection{Experimental Design}

Following List (2007), our design begins by introducing an action set in which the dictator can either give to or take from the recipient's initial endowment and compares outcomes in this augmented game to those observed in the standard dictator game in which the participant can only give to the recipient. We extend this line of inquiry by considering treatments that vary the initial endowments but preserve the feasible set of 
final allocations. ${ }^{5}$ In doing so, we exogenously vary moral reference points, which allows us to identify the importance of such on observed choices. ${ }^{6}$ If the motivation behind choices is driven by final allocations only, variation in the initial endowments within a given feasible set should have no impact on observed dictator behavior. However, if one allows motivations to depend both on final allocations and reference points partly determined by initial allocations, such variation could influence observed behavior.

In each treatment, we varied the amount of what we call the "fixed endowment" an initial endowment to the dictator or recipient that cannot be reallocated by either party, and the amount of "variable endowment" - an initial endowment to the dictator or recipient that can be changed by the actions of the dictator. Varying the fixed endowment allows us to consider the impact of different initial allocations on choices, while varying the variable endowment allows us to consider the effect of changing the action set (of giving or taking). The various endowments used in the experiment are summarized in Table 1.

\section{TABLE 1 ABOUT HERE: SUMMARY OF EXPERIMENT}

Table 1 shows that we have 3 major treatment types: denoted "Inequality," "Equal," and "Envy." The Inequality-Give treatment represents a typical dictator game: both the dictator and recipient have a fixed endowment of 4 units which corresponds to the "show-up fee" in comparable laboratory experiments. In addition, the dictator is provided a variable endowment of 4 units and can choose to share all, some, or none of that amount with the recipient. In the Inequality-Take treatment, the fixed endowment is the same as in the Inequality-Give treatment, but now the "property rights" for the variable endowment are assigned to the recipient rather than the dictator. In the Inequality-Symmetric treatment, we expand the action set by allowing the dictator to either give any portion of her variable endowment ( 0 through 4$)$ or take any portion (0

\footnotetext{
${ }^{5}$ These treatments build upon work by Korenok et al. (2014) and Grossman and Eckel (2015), who employ a variant of the dictator game to explore the effect of give or take actions on choices.

${ }^{6}$ Our approach to identifying the importance of moral reference points shares similarity with Krupka and Weber (2013) who test the importance of norms by comparing final allocations across a standard dictator game and what they call the Bully treatment where the initial endowment is split amongst the dictator and recipient and the dictator is allowed to either give to or take from the recipient. Kimbrough and Vostroknutov (2015) use an alternative approach to identify the importance of norms on dictator behavior by eliciting individual-specific measures of norm-sensitivity and correlating this with observed allocations in the standard dictator game.
} 
through 4) from the recipient's variable endowment. Across all treatments, we restrict the choices of the dictator such that only integer amounts can be shared.

The only difference between the Inequality treatments and the Equal and Envy treatments is that we vary the manner in which the fixed endowment is distributed across the dictator and the recipient. Specifically, in the Equal treatment, we move 2 from the dictator's fixed endowment into the recipient's fixed endowment. In the Envy treatment, we move 4 from the dictator's fixed endowment into the recipient's fixed endowment.

In both the Inequality-Give and the Inequality-Symmetric treatments, the initial endowment of $(8,4)$ favors the dictator and she is thus faced with an allocation decision over a budget set that crosses the 45 degree line, as in most standard dictator games: see Figure 1. In the Equal-Give and Equal-Symmetric treatments, the initial endowment of $(6,6)$ lies on the 45 degree line. However, the treatments differ in that the feasible budget set for the Equal-Give treatment lies on and above the 45 degree line, whereas the feasible budget set for the Equal-Symmetric treatment crosses the 45 degree line. ${ }^{7}$ In the Envy-Give and the Envy-Symmetric treatments, the initial endowment $(4,8)$ lies strictly above the 45 degree line and favors the recipient. Yet, these treatments differ as the feasible budget set for the Envy-Give treatment lies strictly above the 45 degree line, whereas the feasible budget set for the Envy-Symmetric treatment again crosses this line. ${ }^{8}$

\section{FIGURE 1 ABOUT HERE: FEASIBLE SETS}

\subsection{Protocol}

The experiment was conducted at the Chicago Heights Early Childhood Center (CHECC) in the winter of 2013 (see Appendix B). Children were either brought in by parents at a designated time outside normal school hours, or participated during school hours by being taken out of class. All children who participated were assigned the role of the dictator, while children whose parents did not bring them in for the study played the role

\footnotetext{
${ }^{7}$ In this regard, our design shares a similarity with treatment 1 in Cox and Sadiraj (2012) which has dictators make allocations over a budget set that lies on and above the 45 degree line as a means to test a defining characteristic of models of inequality aversion.

${ }^{8}$ Note that "inequality," "equality" and "envy" do not apply literally in the Take treatments, since in the Take treatments the initial endowment always favors the recipient as property rights to the variable endowment are assigned to the recipient. Yet in all such cases, the budget set over which the dictator is selecting a final payoff is identical to that faced in the corresponding Give treatment.
} 
of receivers and were sent their final payoff via the mail.

Each child participated in only one session of the experiment, during which he/she was assigned to either the Inequality, Equal, or Envy treatment. Preschool-age children (ages 3 to 4 ) are predominant in our sample and were randomly assigned to one of the three treatments with equal probability. Kindergarten and $1^{\text {st }}$ grade-age children (ages 5 to 7) were always assigned to the Inequality treatment. We further randomized each child into one of the Give, Symmetric, or Take action sets. After the first decision was paid out, children were surprised with two additional dictator games with the remaining two action sets (which were also paid out). In the text of this paper, we report only between-subjects data from the first choice as it provides the closest link with our theory, which is a model of static choice. ${ }^{9}$

Following prior experiments with very young children (e.g., Li et al., 2013), we used stickers as the payoff medium. To further ensure saliency and dominance of payoffs, the child was first given an option to select one of two predetermined sticker sets as the payoff medium in each dictator game. ${ }^{10}$ In order to conduct the experiment with children, we designed specialized receptacles, as shown in Figure 2. One receptacle belonged to the dictator and the other to the intended recipient. In each treatment, both the dictator and recipient started out with a number of stickers that could not be moved (the fixed endowment). These stickers were housed inside of clear boxes. The stickers available for distribution (the variable endowment) were displayed on plates that were on top of the clear boxes.

\section{FIGURE 2 ABOUT HERE: EXPERIMENT SETUP}

Children could move stickers from plate to plate until a satisfactory final payoff was reached. Once the treatment was completed, the stickers remaining on each plate were moved into the corresponding boxes. Instructions were read aloud by the experimenter to explain how these boxes and plates were to be used. The instructions also included questions to ensure that children understood the game (see Appendix C).

Children received a small toy at the end of the experiment as a "show up fee."

\footnotetext{
${ }^{9}$ Appendix D reports analysis using data from all three choices. Signs of the estimates of the variables of interest (i.e., MMA predictions) are consistent with the ones reported in the text of the paper (that includes only the first task decisions) but the p-values are smaller.

${ }^{10}$ Available sticker types were star or mustache, underwater or space, and cat or dog, respectively, in the first, second, and third dictator games.
} 
The toy was pre-announced in the recruitment letter, but experimenters did not remind children of the toy prior to the start of the experiment. Parents who brought children to the session received $\$ 10$ for their time and an additional $\$ 5$ for completing a short survey while they waited. Each session lasted approximately 10-12 minutes.

\section{Theory Development}

\subsection{Background}

Figure 1 provides a graphical representation of the feasible sets faced by subjects in our dictator games. Giving and Taking action sets provide feasible sets of ordered pairs of integral payoffs contained in $\left[A_{j}, B_{j}\right]$, where $j=Q, I$, and $E$ for the Equal, Inequality, and Envy treatments portrayed by the solid line segments shown in Figure 1. Symmetric action sets provide feasible sets contained in $\left[\mathrm{A}_{\mathrm{j}}, \mathrm{C}_{\mathrm{j}}\right]$, portrayed by the longer line segments (with solid and dashed sub-segments) in Figure $1 .^{11}$

In a Take scenario, the initial endowment is at the northernmost point $A_{j}$ in the (solid-line) set $\left[\mathrm{A}_{\mathrm{j}}, \mathrm{B}_{\mathrm{j}}\right]$, whereas in a Give scenario the initial endowment is at the southernmost point $B_{j}$ in this set. This design choice permits us to test for effects of Give versus Take action sets on final allocations. In the symmetric treatments, the initial allocations are at $\mathrm{B}_{\mathrm{j}}$, and allow the dictator to select an ordered pair of integral payoffs within $\left[A_{j}, C_{j}\right]$.

Self-regarding (or homo economicus) preferences imply the choice of $\mathrm{B}_{\mathrm{j}}$ from $\left[\mathrm{A}_{\mathrm{j}}\right.$, $\left.B_{j}\right]$ and of $C_{j}$ from $\left[A_{j}, C_{j}\right]$. Models of other-regarding preferences predict choices that may differ from $B_{j}$ in set $\left[A_{j}, B_{j}\right]$ and may differ from $C_{j}$ in set $\left[A_{j}, C_{j}\right]$. For strictly convex preferences, one can make additional statements. ${ }^{12}$ When a most preferred allocation $Q_{j}^{*}$ in feasible set $\left[A_{j}, C_{j}\right]$ does not belong to the subset $\left[A_{j}, B_{j}\right]$, then strict convexity requires $B_{j}$ to be the unique most preferred allocation when the budget set is $\left[\mathrm{A}_{\mathrm{j}}, \mathrm{B}_{\mathrm{j}}\right]^{13}$ The statements in this paragraph apply to neoclassical theory of other-

\footnotetext{
${ }^{11}$ We take some license in representing feasible choice sets in Figure 1 as a continuum. However, following Samuelson (1938), our approach is based on observed choices. Hence throughout this paper we will work with finite sets.

${ }^{12}$ Strict convexity of preferences defined on a discrete choice set implies that the most preferred set is either a singleton or a set that contains two adjacent feasible points.

${ }^{13}$ For any given feasible allocation, $\mathrm{X}$ from $\left[\mathrm{A}_{\mathrm{j}}, \mathrm{B}_{\mathrm{j}}\right], \mathrm{B}_{\mathrm{j}}$ is a convex combination of $\mathrm{X}$ and $\mathrm{Q}_{\mathrm{j}}^{*}$ (that belongs to $\left.\left(B_{j}, C_{j}\right]\right)$. Since $Q_{j}^{*}$ is revealed preferred to $X$ in $\left[A_{j}, C_{j}\right]$, by strict convexity $B_{j}$ is strictly preferred to $X$.
} 
regarding preferences (Cox and Sadiraj, 2007) and to popular models of social preferences (e.g., Fehr and Schmidt, 1999; Bolton and Ockenfels, 2000; Charness and Rabin, 2002), but not to some models of warm glow preferences, such as Korenok et al. (2013).

Convexity and rationality, however, are different concepts; rationality requires only that observed choices satisfy certain consistency axioms (see Samuelson, 1938; Chernoff, 1954, Arrow, 1959; Sen, 1971, 1986) as follows. If we let $F^{*}$ denote the choice set (i.e., the set of most-preferred points) when the opportunity set is $F$ and $G^{*}$ be the choice set when the opportunity set is $G$ then the Chernoff (1954) contraction axiom (also known as Property $\alpha$ from Sen 1971) states:

\section{Property $\alpha$ : if $G \subseteq F$ then $F^{*} \cap G \subseteq G^{*}$}

In other words, a most-preferred allocation $f^{*} \in F^{*}$ from feasible set $F$ remains a mostpreferred allocation in any contraction $G$ of the set $F$ that contains the allocation $f^{*}$.

For non-singleton choice sets, a second consistency condition is Sen's (1971) Property $\beta$, which in our notation can be written as:

Property $\beta$ : if $G \subseteq F$ and $G^{*} \cap F^{*} \neq \varnothing$ then $G^{*} \subseteq F^{*}$

In other words, if the most-preferred set $F^{*}$ for feasible set $F$ contains at least one mostpreferred point from the contraction set $G$ then it contains all of the most-preferred points of the contraction set.

For finite sets, Properties $\alpha$ and $\beta$ are necessary and sufficient conditions for a choice function to be rationalizable by a weak order (Sen, 1971). ${ }^{14}$ In case of singlevalued choice functions, Property $\beta$ is automatically satisfied. So we focus on the contraction axiom implications which (for singleton choice sets) in our dictator game experiment are as follows:

Give versus Take Action Set Prediction: If allocation $P_{j}^{*}$ is chosen from the feasible set $\left[A_{j}, B_{j}\right]$ when the action set is Take and the endowment is at $A_{j}$, then $P_{j}^{*}$ is also chosen when the action set is Give and the endowment is at $\mathrm{B}_{\mathrm{j}}$.

\footnotetext{
${ }^{14}$ A weak order is complete and transitive.
} 
Symmetric versus Give or Take Action Set Prediction: If allocation $Q_{j}^{*}$, chosen from the feasible set $\left[\mathrm{A}_{\mathrm{j}}, \mathrm{C}_{\mathrm{j}}\right]$, belongs to the subset $\left[\mathrm{A}_{\mathrm{j}}, \mathrm{B}_{\mathrm{j}}\right]$, then $Q_{j}^{*}$ is also chosen when the feasible set is $\left[A_{j}, B_{j}\right]$.

A behavioral interpretation of the second prediction is straightforward. Choice of $Q_{j}^{*}$ belonging to $\left[\mathrm{A}_{\mathrm{j}}, \mathrm{B}_{\mathrm{j}}\right]$ when the feasible set is $\left[\mathrm{A}_{\mathrm{j}}, \mathrm{C}_{\mathrm{j}}\right]$ reveals that allocations in $\left(\mathrm{B}_{\mathrm{j}}\right.$, $\mathrm{C}_{\mathrm{j}}$ ] are less preferred alternatives than $Q_{j}^{*}$; therefore excluding them from the feasible set should not affect choice. The contraction property has no implication for choice from feasible set $\left[A_{j}, B_{j}\right]$ if the choice from $\left[A_{j}, C_{j}\right]$ is contained in $\left(B_{j}, C_{j}\right]-$ a distinction that has been overlooked in the prior literature. Strictly convex preferences, however, imply that if the chosen point from set $\left[\mathrm{A}_{\mathrm{j}}, \mathrm{C}_{\mathrm{j}}\right]$ is contained in $\left(\mathrm{B}_{\mathrm{j}}, \mathrm{C}_{\mathrm{j}}\right]$ then the chosen point from set $\left[A_{j}, B_{j}\right]$ is $B_{j}$. Data from many dictator game experiments with giving and taking refute strict convexity but not choice rationality. For example, consider Figure 3, which shows data from List (2007). ${ }^{15}$ Previous discussions of these data have focused on comparing the $29 \%$ of choices of 0 in the Baseline treatment with the $65 \%$ of the choices of -1 or 0 in the Take 1 treatment. An implication of strict convexity is that these figures should be (statistically) the same - a pattern that is clearly refuted by the data. ${ }^{16}$ However, convexity is not a necessary condition for choice rationality, so comparison of these $29 \%$ and $65 \%$ figures does not allow the researcher to draw conclusions about choice rationality. An illustration of choices for non-convex preferences is shown in Figure 4. A dictator with such preferences would choose $\mathrm{x}$ from the set $[A, C]$ but switch to $y$ (rather than B) when he faces subset [A, B].

\section{FIGURE 3 ABOUT HERE: HISTOGRAMS FOR LIST AND BARDSLEY DATA}

\section{FIGURE 4 ABOUT HERE: EXAMPLE OF CHOICE WITH NON-CONVEX PREFERENCES}

\footnotetext{
15 The data for List (2007) are from the $J P E$ online appendix.

${ }^{16}$ The initial endowments are the same in these two treatments hence we can discuss implications of convex preference theory for either payoffs or transfers.
} 
The feasible set for the Baseline treatment in List (2007) is a contraction of the set for the Take 1 treatment. Therefore, by the contraction axiom, anyone choosing an amount from 0 to 5 in the Take 1 treatment should make the same choice in the Baseline treatment. In contrast to the special case of convex preferences, rational choice theory offers no suggestions for the Baseline treatment if one is observed to choose -1 in the Take 1 treatment.

The preceding two inferences of rational choice theory together require that each of the bars portraying fractions of choices of 0 to 5 in the Baseline treatment should not be shorter than the corresponding bar for choices in the Take 1 treatment. With the exception of the bar at 1.5 (corresponding to two observations in the Take 1 treatment), the List (2007) data are consistent with rational choice theory. Similarly, data shown in Figures 3 from experiments 1 and 2 conducted by Bardsley (2008) are inconsistent with convex preferences but are mostly consistent with rational choice theory. ${ }^{17}$

As we shall explain in Section 4, data from some of the treatments in our experiment are inconsistent with rational choice theory, which prompts interest in modification of the theory. We next turn our attention to that topic to provide theoretical content to our experimental design and to aid in the interpretation of the data in the empirical results discussion that will follow.

\subsection{Theory of Moral Reference Points}

A framework that has been used to describe giving, taking, and related behaviors builds upon the notion of moral cost (Levitt and List, 2007; List, 2007; Lazear et al., 2012; DellaVigna et al., 2012) or concern for norm compliance (Kessler and Leider, 2012; Krupka and Weber, 2013; Kimbrough and Vostroknutov, 2015). Using this framework, individuals are said to share with others to avoid experiencing moral cost from failing to do so or from taking actions that are deemed socially inappropriate. As in Levitt and List (2007), moral cost may be context dependent and vary with features of the choice problem. ${ }^{18}$ One can easily envision situations in which individuals feel guilty if they

\footnotetext{
${ }^{17}$ Data for Bardsley's Experiment 1 are 100\% consistent with rational choice theory. The bar at 1.5 (2 observations) is the only inconsistency with rational choice theory in Experiment 2 data. Experiment 3 data can be used only to test the special case of convex preferences because the intersection set of the two treatments' feasible sets is a singleton.

${ }^{18}$ Our approach to modeling "moral costs" shares similarity with the revealed altruism model (Cox et al., 2008) whereby feelings of reciprocity and the extent to which an agent feels compelled to act upon them
} 
select actions that are perceived as selfish. But what is deemed selfish may depend on the feasible action set and perceived property rights as inferred through endowment.

Consider, for example, the feasible sets in the middle (Inequality) graph in Figure 1. The lowest feasible payoff for the recipient is 4 in $\left[A_{I}, B_{I}\right]$, and 0 in $\left[A_{I}, C_{I}\right]$. Providing the recipient with payoff of 4 may inflict higher moral cost when the lowest feasible payoff for the recipient is 4 as in the opportunity $\operatorname{set}\left[\mathrm{A}_{\mathrm{I}}, \mathrm{B}_{\mathrm{I}}\right]$ than when the opportunity set is $\left[\mathrm{A}_{\mathrm{I}}, \mathrm{C}_{\mathrm{I}}\right]$, although the final allocation is identical in the two scenarios. Or consider, for example, the feasible set $\left[\mathrm{A}_{\mathrm{I}}, \mathrm{B}_{\mathrm{I}}\right]$ in the middle graph in Figure 1 and the feasible set $\left[A_{E}, C_{E}\right]$ in the right graph in Figure 1. The largest feasible payoff for the recipient is 8 in $\left[\mathrm{A}_{\mathrm{I}}, \mathrm{B}_{\mathrm{I}}\right]$ and 12 in $\left[\mathrm{A}_{\mathrm{E}}, \mathrm{C}_{\mathrm{E}}\right]$. Providing the recipient with a payoff of 6 may inflict higher moral cost when the opportunity set is $\left[A_{E}, C_{E}\right]$ than when the opportunity set is $\left[\mathrm{A}_{\mathrm{I}}, \mathrm{B}_{\mathrm{I}}\right]$, although the final allocation is identical in the two scenarios.

Previous models of moral cost make direct assumptions about the arguments of utility functions. We take an alternate approach and offer an axiomatic model that follows the approach used in Cox and Sadiraj (2010). The idea is to require that choices from feasible sets that preserve moral reference points (defined below) satisfy the contraction axiom and to present a concept of moral reference points that are determined by feasible sets. Throughout our discussion, we use dictator games as an example to illustrate concepts, but the model has general applicability.

Let $(m, y)$ denote (an ordered pair of) payoffs in which my payoff $(m)$ is that of the dictator and your payoff $(y)$ is that of the recipient. Let the dictator's opportunity set be a compact set $F$. Let $m^{o}$ and $y^{o}$ be the maximum feasible payoffs for the dictator and the other player, that is

$$
m^{o}(F)=\sup \{m \mid(m, y) \in F\} \text { and } y^{o}(F)=\sup \{y \mid(m, y) \in F\}
$$

We assume that moral costs are positively correlated with the externality imposed by dictator's choice. Specifically, we assume an agent's moral reference point is a function of the minimal expectations point, $\mathrm{M}$, defined by:

$$
m_{*}(F)=\sup \left\{m:\left(m, y^{o}(F) \in F\right\} \text { and } y_{*}(F)=\sup \left\{y:\left(m^{o}(F), y \in F\right\} .\right.\right.
$$


Moral cost feelings may also depend on the strength of perceived ownership feelings of endowments. To account for this, we propose as a moral reference point an ordered pair that agrees with the minimal expectations point on the second (recipient's) payoff dimension and is a convex combination of the minimal expectations point and the initial endowment $e_{m}$ on the first (dictator's) payoff dimension. For dictator game feasible sets we consider, the moral reference points are given by: ${ }^{19}$

$$
\left.f^{r}=\left(\frac{1}{2} m_{*}(F)+\frac{1}{2} e_{m}\right), y_{*}(F)\right)
$$

Moral reference point together with the Moral Monotonicity Axiom described below, have testable implications for dictator game experiments with contractions of feasible sets or with give or take action sets.

An illustration of moral reference points is provided here for the Give, Take, and Symmetric action sets and Equal, Inequality, and Envy endowment treatments shown in Figure 1. With such downward-sloping budget lines, a moral reference point can be located by: (a) first, finding the minimal expectations point, $\mathrm{M}$, by constructing a right triangle with the hypotenuse being the budget line and the vertical and horizontal sides below and to the left of the budget line; and (b) second, finding the projection of the midpoint of the line segment joining $\mathrm{M}$ and the endowment point on the line segment joining $\mathrm{M}$ and the most selfish point.

The moral reference points for our various treatments are provided in the final column of Table 1. With the Symmetric action set, for example, the moral reference points are, respectively, $(4,2),(6,0)$, and $(2,4)$ in the Equal, Inequality, and Envy treatments. With the Give and Take action sets, the moral reference points are respectively, $(4,6)$ and $(2,6)$ in the Equal treatment, $(6,4)$ and $(4,4)$ in the Inequality treatment, and finally $(2,8)$ and $(0,8)$ in the Envy treatment.

We use action sets shown in Figure 1 to illustrate a behavioral interpretation of moral reference points. The most selfish feasible choice of a dictator in the Symmetric action set for the Inequality treatment, with moral reference point $(6,0)$, is to take all of the recipient's variable endowment and leave her with payoff of 0 . Any choice that gives

\footnotetext{
${ }^{19}$ A less specific definition of the moral reference point is $\left.f^{r}=\left(\theta m_{*}(F)+(1-\theta) e_{m}\right), y_{*}(F)\right)$ where $\theta$ is between 0 and 1 . Any value of $\theta \in(0,1)$ could be used to rationalize all of the contraction and action set effects we discuss in this paper.
} 
the recipient a positive payoff has lower moral cost than giving her zero payoff. Providing the recipient with payoff of 4 , at point $B_{I}$ in the middle graph in Figure 1 , is a generous action when compared to leaving her with 0 . In contrast, the dictator's most selfish feasible action in the Give action set in the Inequality treatment, with moral reference point $(6,4)$, is to give the recipient nothing and provide her with a payoff of 4 . Choosing payoff of 4 for the recipient (and 8 for the dictator) in the Symmetric action set has lower moral cost than choosing 4 in the Give action set which, in turn, has a larger moral cost than choosing 4 in the Take action set in which the moral reference point is $(4,4)$.

It seems natural to assume that dictators' choices that are characterized by moral cost concerns satisfy a monotonicity criterion for moral reference points. We now state an axiom that does this. Using the notation above, let $F^{*}$ be the choice set for feasible set $F$ (and similarly for $G^{*}$ and $G$ ). Let $\left(g_{i}^{r}, g_{-i}^{r}\right)$ and $\left(f_{i}^{r}, f_{-i}^{r}\right)$ be the moral reference points for feasible sets $G$ and $F$, and let $\mathrm{R}$ be the notation for "not smaller" or "not larger." For every agent $i$ one has:

\section{Moral Monotonicity Axiom (MMA):}

$$
\text { If } G \subseteq F, g_{i}^{r} R f_{i}^{r} \text { and } g_{-i}^{r}=f_{-i}^{r} \text { then } f^{*} \in F^{*} \cap G \Rightarrow g_{i}^{*} R f_{i}^{*}, \forall g^{*} \in G^{*}
$$

In words MMA says the following. Suppose that $G$ is a subset of $F$ that contains some choice, $f^{*}$ from $F$. Suppose also that the moral reference points of $F$ and $G$ differ from each other only with respect to the value of dimension $i$. Then if the moral reference point in $G$ is more favorable to individual $i$ then no choice from $G$ allocates him less than $f^{*}$. Similarly, if the moral reference point in $G$ is less favorable to individual $i$ then no choice from $G$ allocates him more than $f^{*}$.

Next consider the implications of MMA for contractions of some set $F$ that preserve moral reference points and intersect with the choice set of $F$. We show that for such subsets MMA implies that the choice set is a singleton and that conventional axioms

of rationality (Sen's 1971 properties $\alpha$ and $\beta$ ) are satisfied. Modified forms of Sen's axioms for sets that preserve the moral reference point are as follows.

Property $\alpha_{M}$ : if $G \subseteq F$ and $g^{r}=f^{r}$ then $F^{*} \cap G \subseteq G^{*}$.

Property $\beta_{M}$ : if $G \subseteq F$ and $g^{r}=f^{r}$ then $G^{*} \cap F^{*} \neq \varnothing$ implies $G^{*} \subseteq F^{*}$ 
We are ready now to state implications of MMA for choices.

Proposition 1: MMA implies Properties $\alpha_{M}$ and $\beta_{M}$

Proof. See Appendix A.

Thus, for opportunity sets that preserve moral reference points MMA suffices for choices to pass both axioms of rationality.

\subsection{Testable Implications of MMA vs. Standard Contraction Axiom}

MMA has many testable implications for the action sets and endowment treatments in our experiment. ${ }^{20}$ We first look at Take versus Give action sets within each individual (Envy, Equal, or Inequality) endowment treatment. In the Inequality treatment, the moral reference point is $(4,4)$ in the Take action set but $(6,4)$ in the Give action set. Therefore, MMA implies that the choice in Take is northwest of the choice in Give, which means the dictator allocates a larger payoff to the recipient in Take than in Give. This contrasts with the implication of conventional rational choice theory that the Give and Take action sets have the same choice set. The same type of argument can be used to show that, in the Envy and Equal endowment treatments, MMA implies a larger allocation to the recipient in the Take than in the Give action set whereas conventional theory implies identical allocations in Give and Take.

Next consider predictions for cases in which the contraction set is a proper subset of another feasible set. We begin with the Envy treatment that provides four direct tests, follow up with a discussion of the Equal treatment that permits two direct tests, and finish with the Inequality treatment that offers only one direct test. As the Envy-Symmetric treatment provides the richest setting we will provide a figure for budget sets involved in the discussion to make the reading of the following paragraph easier.

Recall that the feasible set, $\left[\mathrm{A}_{\mathrm{E}}, \mathrm{C}_{\mathrm{E}}\right]$ in the Envy-Symmetric design contains allocations that range from a high payoff of 8 to a low payoff of 0 for the dictator (see Figure 1), with the initial allocation being $(4,8)$. One can easily verify (see Figure 5) that sets $\left[A_{E}, B_{E}\right]$ (dashed light blue segment in Figure 5) in the Envy treatment, $\left[A_{Q}, B_{Q}\right]$ (dashed red segment in Figure 5) in the Equal treatment, and $\left[\mathrm{A}_{\mathrm{I}}, \mathrm{B}_{\mathrm{I}}\right]$ (dashed-dot black

20 In developing the implications of MMA for dictator games, we assume that a dictator prefers higher to lower own money payoff, ceteris paribus. 
segment in Figure 5) in the Inequality treatment are all proper subsets of $\left[A_{E}, C_{E}\right]$ (solid line in Figure 5). The standard contraction axiom requires dictator's choice in $\left[A_{E}, C_{E}\right]$ to be preserved when the dictator's feasible set contracts to sets that contain that choice. Note, however, that with respect to the moral reference point, $f_{E}^{S}=(2,4)$ for EnvySymmetric, the moral reference points of contractions are monotonically ordered (in a way that makes possible a direct application of MMA) for the following cases: EqualTake with $\mathrm{f}_{\mathrm{Q}}^{\mathrm{t}}=(2,6)$, Envy-Give with $\mathrm{f}_{\mathrm{E}}^{\mathrm{g}}=(2,8)$, Inequality-Take with $\mathrm{f}_{\mathrm{I}}^{\mathrm{t}}=(4,4)$ and Inequality-Give with $\mathrm{f}_{\mathrm{I}}^{\mathrm{g}}=(6,4)$. MMA requires that dictators' choices in the EnvySymmetric set, $\left[A_{E}, C_{E}\right]$ that belong to the subset: (i) $\left[A_{Q}, B_{Q}\right]$ move northwest when the feasible set is the one in Equal-Take; (ii) $\left[\mathrm{A}_{\mathrm{E}}, \mathrm{B}_{\mathrm{E}}\right]$ move northwest when the feasible set is the one in Envy-Give, and (iii) $\left[\mathrm{A}_{\mathrm{I}}, \mathrm{B}_{\mathrm{I}}\right]$ move southeast when the feasible sets are the ones in Inequality-Take and Inequality-Give.

\section{FIGURE 5 ABOUT HERE: REFERENCE POINTS FOR CONTRACTION SETS}

Next, in the Equal-Symmetric treatments the feasible set contains allocations between $(10,2)$ and $(2,10)$ (see $\left[\mathrm{A}_{\mathrm{Q}}, \mathrm{C}_{\mathrm{Q}}\right]$ in Figure 1) with $(6,6)$ as the initial allocation. Available contractions in our experiments are sets $\left[\mathrm{A}_{\mathrm{Q}}, \mathrm{B}_{\mathrm{Q}}\right]$ in the Equal treatment and $\left[\mathrm{A}_{\mathrm{I}}, \mathrm{B}_{\mathrm{I}}\right]$ in the Inequality treatment. The standard contraction axiom requires dictator's choices in $\left[\mathrm{A}_{\mathrm{Q}}, \mathrm{C}_{\mathrm{Q}}\right]$ to not be affected when the dictator's feasible set contracts to subsets that contain it. Note that the moral reference point is $(4,2)$ for Equal-Symmetric whereas moral reference points of contractions are $(4,6)$ for Equal-Give and $(4,4)$ for InequalityTake. MMA then requires that dictators' choices in the Equal-Symmetric set, $\left[\mathrm{A}_{\mathrm{Q}}, \mathrm{C}_{\mathrm{Q}}\right]$ that belong to the subset: (i) $\left[\mathrm{A}_{\mathrm{Q}}, \mathrm{B}_{\mathrm{Q}}\right]$ move northwest when the dictator faces EqualTake, and (ii) $\left[\mathrm{A}_{\mathrm{I}}, \mathrm{B}_{\mathrm{I}}\right]$ move northwest in Inequality-Take.

Finally, in the Inequality-Symmetric treatment with feasible set $\left[\mathrm{A}_{\mathrm{I}}, \mathrm{C}_{\mathrm{I}}\right]$ (see Figure 1) the only available contraction in our experiment is the set $\left[\mathrm{A}_{\mathrm{I}}, \mathrm{B}_{\mathrm{I}}\right]$ in the same treatment. The standard contraction axiom requires dictator's choices from the Symmetric $\left[\mathrm{A}_{\mathrm{I}}, \mathrm{C}_{\mathrm{I}}\right]$, contained in $\left[\mathrm{A}_{\mathrm{I}}, \mathrm{B}_{\mathrm{I}}\right]$, be preserved when the dictator encounters Inequality-Give action set whereas MMA predicts a northwest move as the moral reference points are $(6,4)$ in the latter and $(6,0)$ in the former. With these predictions in mind, we turn to the experimental results. 


\section{Experimental Results}

\subsection{Overview}

329 children participated in our experiment. The average age of our subjects was 5 , with the majority of children below the age of 5 (183); the minimum age was 3.5 and maximum age was 7.4 years old. In our sample, we have 50\% males, 44\% Hispanic, $42 \%$ African-American, and 12\% Caucasian. We do not have a race on file for the remaining $2 \%$ of subjects. Treatments are balanced on demographics, with the exception of the Inequality treatment, which is unbalanced on age by design, as aforementioned. ${ }^{21}$

Table 2 provides key summary statistics for our experiment - average transfer amounts and final payoffs that dictators chose in each treatment. Figure 6 summarizes the disaggregated data by providing histograms of total payoff to the dictator by treatment and action set. Combined, Table 2 and Figure 6 give rise to several important observations. First, in each setting (Inequality, Equal, Envy) the final dictator ownpayoff in the Give action set is never smaller than that observed in the Take action set. Second, in each setting the dictator own payoff in the Symmetric action set is always larger than that observed in the Give action set. Finally, children respond to player favoritism of fixed endowment - transfers as a function of the variable endowment are greatest under the Inequality treatment and lowest in the Envy treatment.

TABLE 2 ABOUT HERE: SUMMARY STATISTICS

\section{FIGURE 6 ABOUT HERE: HISTOGRAMS FOR DICTATOR PAYOFFS}

\subsection{Effects of Give vs. Take Action Sets}

We now turn to testing how well the empirical data support the Moral Monotonicity Axiom. As we explain in Section 3, data reported in List (2007) and Bardsley (2008) are at odds with convex preferences. However, as the "Give" and "Give or Take" treatments in these papers change the action set in a way that does not preserve the opportunity set,

\footnotetext{
${ }^{21}$ Conducting regressions (that include experimenter fixed effects) of all treatment dummies with either gender or race (separately for African-American, Hispanic, or White) does not yield any significant coefficients. Conducting similar regressions with age at time of the test as the dependent variable for each treatment Inequality, Equal, or Envy, does not yield significant differences by action set.
} 
one cannot ascertain whether differences in choices across treatments reflect a violation of rationality (contraction axiom).

Our experimental treatments are carefully designed to permit an exploration of this basic tenet, and to parse the importance of Give vs. Take actions. Specifically, in an important departure from the designs implemented in List and Bardsley, which change both feasible sets and action sets, our experiment preserves the feasible set but allows both giving and taking. We show that this departure is fundamental in providing a test of the contraction axiom.

Standard rational choice theory implies that choices in opportunity sets $\left[\mathrm{A}_{\mathrm{j}}, \mathrm{B}_{\mathrm{j}}\right]$ are invariant to the Give and Take action set designs. In contrast, MMA implies that dictator's own-payoff cannot be lower in the Give action set than in the Take action set. Inspection of Figure 6 suggests that the data are skewed in a direction consistent with MMA in two out of our three treatments, the Equal and Envy treatments. In the Equal setting, we observe a higher mode in the Give (mode $=6$ ) than the Take (mode $=4$ ) action set. In the Envy treatment, the modal choice is the same in Give and Take (4), but it attracts $70 \%$ of the choices in the Give action set versus less than $45 \%$ in the Take action set. Examining the final payoffs column in Table 2, we see that, on average, dictators' payoffs are 0.50 larger in the Give setting than in the Take setting.

To further explore if the Give versus Take action sets affect final allocations, we run hurdle regression models, since the dependent variable, dictator's payoff, is bounded by the design of the experiment (Cragg, 1971). ${ }^{22}$ The list of regressors includes dummies for the Give action set and experimenter fixed effects. In all models, we exclude data on payoffs for choices made under the Symmetric action set.

Table 3 reports conditional marginal effects for the Give action set on the dictator's final payoffs. As can be noted from the table, average payoffs for a dictator assigned to the Give only action set are approximately 0.40 greater (p-value $=0.064$ ) in the Inequality treatment, 0.25 greater $(p$-value $=0.450)$ in the Equal treatment, and 1.17 greater $(p$-value $=0.010)$ in the Envy treatment. Hence, we find evidence that the

\footnotetext{
${ }^{22}$ The use of the hurdle model to test the predictions of our theory is appealing as it does not rely upon the assumption of a data generating process akin to that which would be observed under a model of convex preferences as would be the case if we used alternative models such as the Tobit.
} 
assignment of endowments and the corresponding (Give versus Take) action set affects choices and the resulting distribution of final payoffs. This provides our first result.

Result 1: Effects on choices from within-treatment changes from Give to Take action sets are (weakly) inconsistent with conventional rational choice theory but consistent with our model based on MMA

\section{TABLE 3 ABOUT HERE: TESTING GIVE VERSUS TAKE ACTION SETS}

\subsection{Effects of Contractions of Feasible Sets}

We next report results from a test that discriminates between the implications of the contraction axiom of conventional choice theory and the implications for contraction under the Moral Monotonicity Axiom (MMA). As discussed in Section 3, the contraction axiom for conventional theory requires preservation of choices from the set $\left[\mathrm{A}_{\mathrm{j}}, \mathrm{C}_{\mathrm{j}}\right]$ that belong to the subset $\left[\mathrm{A}_{\mathrm{j}}, \mathrm{B}_{\mathrm{j}}\right]$ when the opportunity set is the latter. In contrast, rather than preservation, MMA requires higher generosity in Give and even higher generosity in Take.

To test our theoretical predictions, we use data from the Give and Take action sets and examine the choices for each feasible action in the set $\left[\mathrm{A}_{j}, \mathrm{~B}_{\mathrm{j}}\right]$ across our Symmetric and Give or Take data. To test the significance of these differences, we utilize a hurdle model using all choices from Give and Take action sets and only data from the Symmetric action set that belong to $\left[\mathrm{A}_{\mathrm{j}}, \mathrm{B}_{\mathrm{j}}\right]$.

Table 4 reports conditional mean estimates of action set on dictators' final payoffs. ${ }^{23}$ Data from the Inequality treatment reveal a negative effect (consistent with MMA) of Give and Take action sets on dictator's payoff: 0.93 lower (p-value $=0.00$ ) for Give and 1.29 lower $(\mathrm{p}$-value $=0.00)$ for Take. Data from our Equal and Envy treatments tell the exact same story. Five of the negative coefficients are significant at

\footnotetext{
${ }^{23}$ An alternative way to test for inconsistencies with the conventional contraction axiom is to compare the frequency of choices at each point in the range $\left[\mathrm{A}_{\mathrm{j}}, \mathrm{B}_{\mathrm{j}}\right]$ across the Give, Take and Symmetric versions of each game. Recall that under the contraction axiom, the frequency of choice at any point in this range in the Symmetric version of the game cannot be greater than that observed in the Give or Take version. Results from these tests are consonant with those obtained under the Hurdle model and show that observed data is at odds with the contraction axiom - e.g., the frequency of choices that leave the dictator with 8 stickers in the Inequality treatments is significantly greater under the Symmetric action set than under either the Give or Take action sets.
} 
the $\mathrm{p}<.01$ level; only one coefficient is not significantly different from 0 . These estimates provide a second result:

Result 2: Effects on choices from within-treatment contractions of feasible sets are consistent with MMA.

\section{TABLE 4 ABOUT HERE: TESTS SUPPORTING RESULT 2}

MMA also has key testable implications across our experimental treatments. Given the design of our treatments, we can use MMA to generate specific predictions of differences in choices that follow from the locations of the moral reference points, as illustrated in Figure 5. The conventional contraction axiom requires that the conditional mean estimates of action sets on dictator's payoff are statistically indistinguishable from 0. MMA, in contrast, has two key types of predictions. First, it predicts positive estimates in the case of contraction of the feasible set in Symmetric Envy $\left[A_{E}, C_{E}\right]$ to the feasible sets in Inequality Take and even larger in Inequality Give action set $\left[\mathrm{A}_{\mathrm{I}}, \mathrm{B}_{\mathrm{I}}\right]$. Second, it predicts a negative estimate in the case of contraction of the feasible set in Symmetric Equal $\left[\mathrm{A}_{\mathrm{Q}}, \mathrm{C}_{\mathrm{Q}}\right]$ to the feasible set for Inequality Take $\left[\mathrm{A}_{\mathrm{I}}, \mathrm{B}_{\mathrm{I}}\right]$.

\section{TABLE 5 ABOUT HERE: TESTS SUPPORTING RESULT 3}

Table 5 reports between-treatment comparisons of contraction. The bottom row of Table 5 reports means for predictions based on the moral reference points shown in Figure 5. All comparisons of means are in the direction predicted by MMA. More specifically, conditional mean estimates reported in Table 5 are consistent with MMA

predictions for the Envy-Symmetric contractions at the $p<.01$ level. The signs of the estimates are in the right direction for Inequality-Take contraction of Symmetric-Equal but the estimates are not different from 0 at conventional levels of significance. This provides our next result.

Result 3: Between-treatment contractions of feasible sets produce effects on choices that are consistent with MMA. 
In summary, our data provide empirical support for MMA. In contrast, the data call into question the standard model of rational choice and models of social preferences that assume convex preferences to describe behavior in sharing games.

\section{Broader Implications of MMA}

To formalize the ways in which moral reference points may influence decision-making in dictator games, we have introduced the Moral Monotonicity Axiom (MMA) and applied it to analyze data from our experiment. Yet, MMA has broader implications for choice in a range of related experiments including standard (give-only) dictator games (Andreoni and Miller, 2002) and other dictator games that compare the effect of give versus take actions on choices (Korenok et al., 2014).

As previously mentioned, in a seminal study Andreoni and Miller (2002) conducted dictator game experiments that vary underlying budget sets and apply the generalized axiom of revealed preference (GARP) to analyze the consistency of choices in their setting. Figure 7 illustrates two budget sets like those that the dictator can face in the Andreoni and Miller design. Let point $a$ denote the endowment on the steeper line and point $b$ denote the endowment on the flatter line. Further, consider the shaded quadrilateral that is the intersection of sets bounded by the steeper and flatter budget lines. Viewed through the lens of MMA, the shaded quadrilateral set can be considered a feasible set with endowment at point $a$. The minimal expectations point is the origin $(0,0)$ for all three feasible sets. Therefore, the moral reference points for the three feasible sets are on the horizontal axis, halfway between 0 and the respective endowment points. The moral reference point $f_{b}$ for the budget set represented by the flatter budget line is more favorable to the dictator than the moral reference point $f_{a}$ for the set represented by the steeper budget line.

\section{FIGURE 7 ABOUT HERE: MMA AND WARP}

Now consider two choices A and B from the original sets that violate the weak axiom of revealed preference (WARP). Suppose that the dictator chooses A on the steeper budget line. Then MMA (see Proposition 1) requires that A also be chosen from the quadrilateral set because it is a contraction of the feasible set represented by the 
steeper line that preserves the moral reference point. Suppose that B is chosen from the lower flat triangle. MMA requires that the choice in the quadrilateral (which is also a contraction of the lower flat triangle) allocates to the dictator less than B does, because $f^{a}$ is to the left of $f^{b}$. But this contradicts the choice of A from the quadrilateral set. Thus, any pair of choices of type A and B violate MMA, i.e., the implication of MMA for such budget sets is the same as the implication of WARP. Importantly, this implies that a researcher need not appeal to different theoretical models to rationalize data from the Andreoni and Miller (2002) experiment and the experiment reported herein. Our theory based on MMA can rationalize data from both experiments.

In a related vein, Korenok et al. (2014) report a dictator game experiment to test the theoretical model of warm glow developed by Korenok et al. (2013). In particular, they explore the effects of changing endowments and framing actions as giving to or taking from the recipient. Korenok et al. (2014) explain that data from their experiment is inconsistent with the predictions of their theory, which, in this instance, are the same as the predictions of the conventional rational choice model.

Yet, their exhibited data patterns are consonant with our theory of moral costs. ${ }^{24}$ Figure 8 illustrates five different scenarios in the Korenok et al. (2014) experiment. In all five scenarios, the feasible set is the same set of discrete points on the budget line shown in Figure 8. What varies across scenarios is the initial (endowed) allocation of $\$ 20$ between the dictator and the recipient. We represent these scenarios using the numbered points on the budget line in Figure 8. For example, in scenario 1, the dictator is endowed with $\$ 20$ and the recipient with $\$ 0$. In scenario 9, the recipient is endowed with $\$ 20$ and the dictator with $\$ 0$. Other endowments used in the experiment are shown at points 3,6, and 8 on the budget line in Figure 8.

\section{FIGURE 8 ABOUT HERE: ENDOWMENTS \& MORAL REFERENCE POINTS}

\footnotetext{
${ }^{24}$ Although we use the Korenok et al. (2014) data to explore implications of alternative theories, caution is called for in basing conclusions on those data because the payoff protocol used in the experiment is not incentive compatible. Their experiment involves role reversal in which each subject plays both dictator and recipient and is paid for both decisions. This payoff protocol might create an incentive for strategic behavior, not an incentive for truthful reporting of distributional preferences. Korenok et al. (2013), aware of this issue, report that this payoff protocol did not introduce significant bias in their experiment. Incentive compatibility of alternative payoff protocols is examined at length in Cox et al. (2015).
} 
The Korenok et al. (2013) theory and conventional rational choice theory both imply that choices will be invariant to changes in the endowments in the experiment. In contrast, our theory implies that choices will monotonically track changes in the underlying endowment points. To see this, note that the minimal expectations point is the origin $(0,0)$ in all of the scenarios. Hence, the corresponding moral reference points for all scenarios are on the horizontal axis, halfway between 0 and the dictator's endowments for each of the respective scenarios. We have illustrated the various moral reference points in Figure 8 as $f_{j}$, for scenarios $j=1,3,6,8,9$. MMA implies that choices monotonically move northwest as the endowment moves northwest along the budget line.

Let $\mathrm{S} 1(\$ 4.05)$ denote the average payoff of $\$ 4.05$ to the recipient in scenario 1 . Using this same convention to reflect payoffs in the remaining scenarios, we have that the average recipient payoffs for the five scenarios are: S1 (\$4.05), S3 (\$5.01), S6 (\$5.61), S8 (\$6.59), and S9 (\$6.31). The fact that average payoffs differ across endowments is inconsistent with predictions from the Korenok et al. (2013) theory and conventional rational choice theory. Importantly, however, the observed changes are as predicted by our theory except for the decrease from $\$ 6.59$ to $\$ 6.31$ between scenario 8 and scenario 9 - a difference that Korenok et al. report to be statistically insignificant at conventional levels.

Finally, MMA predicts both dictator game choices and social norms elicited by Krupka and Weber (2013). In their experiment the moral reference point is $(5,0)$ in the standard dictator game and $(2.5,0)$ in the bully dictator game. Hence, MMA requires choices in the bully treatment to be drawn from a distribution that is less favorable to the dictator than the distribution of choices in the standard game. Therefore, we expect a higher amount allocated to the recipient and a positive estimate of the bully treatment in an ordered logistic regression. The reported mean amounts allocated to the recipients are $\$ 2.46$ (standard) and \$3.11 (bully) and the coefficient estimate for the bully treatment is significantly positive (see their Table 2 ). ${ }^{25}$ Because the minimal expectations point in both their standard and bully dictator games is the natural origin, the only way in which a moral reference point varies is with the change in endowments from $(10,0)$ to $(5,5)$. In

\footnotetext{
${ }^{25}$ Distributions of elicited norms reported in Krupka and Weber's Table 1 are also consistent with MMA. A paired t-test of the two distributions rejects the null hypothesis of no effect (standard contraction axiom) in favor of the MMA-consistent alternative hypothesis (of approval of higher allocations to recipients): $\mathrm{t}=5.34$, one-sided $\mathrm{p}=0.0002, \mathrm{~N}=11$ ).
} 
contrast within each of our three treatments, we hold the endowment constant but vary the minimal expectations point. Results reported in Table 4 (Give Action set row) clearly show the significant effects on choices of changing the moral reference point while holding the endowment constant.

\section{Concluding Remarks}

When faced with the opportunity to share resources with a complete stranger, when and why do we give? The dictator game has emerged as a key data generator to provide researchers with a simple approach for eliciting other-regarding preferences in a controlled setting. The game has worked well in the sense that we now understand giving behaviors at a much deeper level. What has been less well explored is whether received choices violate the basic foundations of economic theory.

Recent dictator game experiments reveal that choices of subjects in specific pairs of dictator games are inconsistent with convex preference theory (List, 2007; Bardsley, 2008; Cappelen et al., 2013). But the designs of these experiments do not provide an empirical challenge to rational choice theory. We take this next step by designing an experiment that generates data to test the empirical implications of the contraction axiom that is central to the theory. We find data that are inconsistent with extant rational choice theory. Fortunately, our experimental design and data suggest why, and how, rational choice theory needs to be extended to maintain consistency with our data patterns.

In this spirit, we propose moral reference points as features of feasible sets and a moral monotonicity axiom (MMA). An implication of MMA is preservation of the contraction property of rational choice theory for feasible sets and subsets that have the same moral reference point. While we are not the first to suggest the importance of moral costs on choices or to develop a model of such, prior efforts have relied upon assumptions of particular forms for utility functions. Our model, in contrast, is based on an extension of the standard model of rational choice and is able to reconcile data that are at odds with extant rational choice theory and data that maintain consistency with convex preference theory (e.g., GARP).

The model and experimental data lead us to conclude that moral reference points play a major role in the decision to act generously. Moreover, our finding that moral reference points play a role in the decisions of young children suggests that such 
preferences may be innate or acquired early in life. As a whole, these findings highlight the importance of revisiting standard models to explore the role of moral reference points in a broader array of choice settings. In this manner, we view our results as having both positive and normative import. For empiricists and practitioners, the results herein provide an indication that moral costs can play an important role in welfare calculations and program evaluation. 


\section{References}

Andersen, Steffen, Seda Ertaç, Uri Gneezy, Moshe Hoffman, and John A. List. "Stakes Matter in Ultimatum Games." American Economic Review 101, no. 7 (2011): 3427-3439.

Andreoni, James, and John H. Miller. "Rational Cooperation in the Finitely Repeated Prisoner's Dilemma: Experimental Evidence.” Economic Journal 103, no. 418 (1993): 570-585.

Andreoni, James, and John H. Miller. "Giving According to GARP: An Experimental Test of the Consistency of Preferences for Altruism." Econometrica 70, no. 2 (2002): 737-753.

Arrow, Kenneth J. "Rational Choice Functions and Orderings." Economica 26, no. 102 (1959): 121-127.

Bardsley, Nicholas. "Dictator Game Giving: Altruism or Artefact?" Experimental Economics 11, no. 2 (2008): 122-133.

Benenson, Joyce F., Joanna Pascoe, and Nicola Radmore. "Children's Altruistic Behavior in the Dictator Game." Evolution and Human Behavior 28, no. 3 (2007): 168-175.

Bolton, Gary E., and Axel Ockenfels. "ERC: A Theory of Equity, Reciprocity, and Competition." American Economic Review 90, no. 1 (2000): 166-193.

Cappelen, Alexander W., Ulrik H. Nielsen, Erik Ø. Sørensen, Bertil Tungodden, and Jean-Robert Tyran. "Give and Take in Dictator Games." Economics Letters 118, no. 2 (2013): 280-283.

Charness, Gary, and Matthew Rabin. "Understanding Social Preferences with Simple Tests." Quarterly Journal of Economics 117, no. 3 (2002): 817-869.

Chernoff, Herman. "Rational Selection of Decision Functions." Econometrica 22, no. 4 (1954): 423-443.

Choi, Syngjoo, Douglas Gale, Ray Fisman, and Shachar Kariv. "Consistency and Heterogeneity of Individual Behavior under Uncertainty." American Economic Review 97, no. 5 (2007): 1921-1938.

Cox, James C., Daniel Friedman, and Vjollca Sadiraj. "Revealed Altruism." Econometrica 76, no. 1 (2008): 31-69.

Cox, James C., and David M. Grether. "The Preference Reversal Phenomenon: Response Mode, Markets and Incentives." Economic Theory 7, no. 3 (1996): 381-405. 
Cox, James. C., and Vjollca Sadiraj. "On Modeling Voluntary Contributions to Public Goods." Public Finance Review 35, no. 2 (2007): 311-332.

Cox, James C., and Vjollca Sadiraj. "A Theory of Dictators' Revealed Preferences." Paper presented at the Biennial Social Dilemmas Conference, Rice University (2010).

Cox, James C., and Vjollca Sadiraj. "Direct Tests of Individual Preferences for Efficiency and Equity." Economic Inquiry 50, no.4 (2012): 920-931.

Cox, James C., Vjollca Sadiraj, and Ulrich Schmidt. "Paradoxes and Mechanisms for Choice under Risk." Experimental Economics 18, no. 2 (2015): 215-250.

Cragg, John G. "Some Statistical Models for Limited Dependent Variables with Application to the Demand for Durable Goods." Econometrica 39, no. 5 (1971): 829-844.

DellaVigna, Stefano, John A. List, and Ulrike Malmendier. "Testing for Altruism and Social Pressure in Charitable Giving." Quarterly Journal of Economics 127, no. 1 (2012): 1-56.

Dufwenberg, Martin, and Georg Kirchsteiger. "A Theory of Sequential Reciprocity." Games and Economic Behavior 47, no. 2 (2004): 268-298.

Engel, Christoph. "Dictator Games: A Meta Study." Experimental Economics 14, no. 4 (2011): 583-610.

Engelmann, Dirk, and Guillaume Hollard. "Reconsidering the Effect of Market Experience on the "Endowment Effect"." Econometrica 78, no. 6 (2010): 20052019.

Fehr, Ernst, Helen Bernhard, and Bettina Rockenbach. "Egalitarianism in Young Children." Nature 454, (2008): 1079-1083.

Fehr, Ernst, Georg Kirchsteiger, and Arno Riedl. "Does Fairness Prevent Market Clearing? An Experimental Investigation." Quarterly Journal of Economics 108, no. 2 (1993): 437-459.

Fehr, Ernst, and Klaus M. Schmidt. "A Theory of Fairness, Competition, and Cooperation." Quarterly Journal of Economics 114, no. 3 (1999): 817-868.

Ferraro, Paul J., and Michael K. Price. "Using Nonpecuniary Strategies to Influence Behavior: Evidence from a Large-Scale Field Experiment." Review of Economics and Statistics 95, no. 1 (2013): 64-73. 
Fisman, Ray, Shachar Kariv, and Daniel Markovits. "Individual Preferences for Giving." American Economic Review 97, no. 5 (2007): 1858-1876.

Fisman, Ray, Pam Jakiela, and Shachar Kariv. "How Did the Great Recession Impact Social Preferences." Journal of Public Economics 128 (2015): 84-95.

Frederick, Shane, George Loewenstein, and Ted O'Donoghue. "Time Discounting and Time Preference: A Critical Review." Journal of Economic Literature 40, no. 2 (2002): 351-401.

Grossman, Philip J. and Catherine C. Eckel, "Giving vs. Taking for a Cause." Economics Letters 132 (2015): 28-30.

Harbaugh, William T., Kate Krause, and Steven G. Liday, Jr. "Bargaining by Children." Working Paper (2003).

Harless, David W. "Predictions about Indifference Curves inside the Unit Triangle: A Test of Variants of Expected Utility Theory." Journal of Economic Behavior \& Organization 18, no. 3 (1992): 391-414.

Hey, John D. "Experimental Investigations of Errors in Decision Making under Risk." European Economic Review 39, no. 3-4 (1995): 633-640.

Hey, John D., and Chris Orme. "Investigating Generalizations of Expected Utility Theory Using Experimental Data." Econometrica 62, no. 6 (1994): 1291-1326.

Hicks, John R. Value and Capital. Oxford: Clarendon Press. (1946).

Kahneman, Daniel, Jack L. Knetsch, and Richard H. Thaler. "Fairness and the Assumptions of Economics." Journal of Business 59, no. 4 (1986): 285-300.

Kahneman, Daniel, Jack L. Knetsch, and Richard H. Thaler. "Experimental Tests of the Endowment Effect and the Coase Theorem." Journal of Political Economy 98, no. 6 (1990): 1325-1348.

Kessler, Judd B. and Leider, Stephen. "Norms and Contracting." Management Science 58, no. 1 (2012): 62-77.

Kimbrough, Erik O., and Alexander Vostroknutov. "Norms Make Preferences Social." Journal of the European Economic Association, (2015): Forthcoming.

Korenok, Oleg, Edward L. Millner, and Laura Razzolini. "Impure Altruism in Dictators' Giving." Journal of Public Economics 97, (2013): 1-8.

Korenok, Oleg, Edward L. Millner, and Laura Razzolini. "Taking, Giving, and Impure Altruism in Dictator Games." Experimental Economics 17, no. 3 (2014): 488500. 
Krupka, Erin L. and Roberto A. Weber. "Identifying Social Norms using Coordination Games: Why does Dictator Game Sharing vary?" Journal of the European Economic Association 11, no. 3 (2013): 495-524.

Laibson, David. "Golden Eggs and Hyperbolic Discounting." Quarterly Journal of Economics 112, no. 2 (1997): 443-478.

Landry, Craig E., Andreas Lange, John A. List, Michael K. Price, and Nicholas G. Rupp. "Is a Donor in Hand Better Than Two in the Bush? Evidence from a Natural Field Experiment." American Economic Review 100, no. 3 (2010): 958-983.

Lazear, Edward P., Ulrike Malmendier, and Roberto A. Weber. "Sorting in Experiments with Application to Social Preferences." American Economic Journal: Applied Economics 4, no. 1 (2012): 136-163.

Levitt, Steven D., and John A. List. "What Do Laboratory Experiments Measuring Social Preferences Reveal About the Real World?" Journal of Economic Perspectives 21, no. 2 (2007): 153-174.

Li, Yiyuan, Hong Li, Jean Decety, and Kang Lee. "Experiencing a Natural Disaster alters Children's Altruistic Giving." Psychological Science 24, no. 9 (2013): 1686-1695.

List, John A. "Preference Reversals of a Different Kind: The "More Is Less" Phenomenon." American Economic Review 92, no. 5 (2002): 1636-1643.

List, John A. "Testing Neoclassical Competitive Theory in Multilateral Decentralized Markets." Journal of Political Economy 112, no. 5 (2004): 1131-1156.

List, John A. "On the Interpretation of Giving in Dictator Games." Journal of Political Economy 115, no. 3 (2007): 482-493.

List, John A., and Anya C. Samek. "Exploring the Origins of Charitable Acts: Evidence from an Artefactual Field Experiment with Young Children." Economics Letters 118, no. 3 (2013): 431-434.

O'Donoghue, Ted, and Matthew Rabin. "Doing It Now or Later." American Economic Review 89, no. 1 (1999): 103-124.

O'Donoghue, Ted, and Matthew Rabin. "Choice and Procrastination." Quarterly Journal of Economics 116, no. 1 (2001): 121-160.

Rabin, Matthew. "Incorporating Fairness into Game Theory and Economics." American Economic Review 83, no. 5 (1993): 1281-1302.

Samuelson, Paul A. "A Note on the Pure Theory of Consumer's Behavior." Economica 5, no. 17 (1938): 61-71. 
Samuelson, Paul A. Foundations of Economic Analysis. Cambridge, MA: Harvard University Press, 1947.

Sen, Amartya K. "Choice Functions and Revealed Preference." Review of Economic Studies 38, no. 3 (1971): 307-317.

Sen, Amartya K. "Social Choice Theory." in Handbook of Mathematical Economics, vol. III, ed. by K. J. Arrow and M. Intriligator. Amsterdam: North-Holland (1986).

Slovic, Paul. "The Construction of Preference." American Psychologist 50, no. 5 (1995): 364-371.

Tversky, Amos. "Intransitivity of Preferences." Psychological Review 76, no. 1 (1969): $31-48$.

Zhang, Le, and Andreas Ortmann. "The Effects of Take-Option in Dictator-Game Experiments: A Comment on Engel's (2011) Meta-study." Experimental Economics 17, no. 3 (2014): 414-420. 


\section{TABLES}

Table 1: Summary of Treatments (Dictator's Endowment, Recipient's Endowment)

\begin{tabular}{|l|l|l|l|l|l|}
\hline & & $\begin{array}{l}\text { Fixed } \\
\text { Endowment }\end{array}$ & $\begin{array}{l}\text { Variable } \\
\text { Endowment }\end{array}$ & $\begin{array}{l}\text { Total } \\
\text { Endowment }\end{array}$ & $\begin{array}{l}\text { Moral } \\
\text { Reference } \\
\text { Point }\end{array}$ \\
\hline \multirow{4}{*}{ Inequality } & Give & $(4,4)$ & $(4,0)$ & $(8,4)$ & $(6,4)$ \\
\cline { 2 - 6 } & Take & $(4,4)$ & $(0,4)$ & $(4,8)$ & $(4,4)$ \\
\cline { 2 - 6 } & Symmetric & $(4,0)$ & $(4,4)$ & $(8,4)$ & $(6,0)$ \\
\hline \multirow{5}{*}{ Equal } & Give & $(2,6)$ & $(4,0)$ & $(6,6)$ & $(4,6)$ \\
\cline { 2 - 6 } & Take & $(2,6)$ & $(0,4)$ & $(2,10)$ & $(2,6)$ \\
\cline { 2 - 6 } & Symmetric & $(2,2)$ & $(4,4)$ & $(6,6)$ & $(4,2)$ \\
\hline \multirow{5}{*}{ Envy } & Give & $(0,8)$ & $(4,0)$ & $(4,8)$ & $(2,8)$ \\
\cline { 2 - 6 } & Take & $(0,8)$ & $(0,4)$ & $(0,12)$ & $(0,8)$ \\
\cline { 2 - 6 } & Symmetric & $(0,4)$ & $(4,4)$ & $(4,8)$ & $(2,4)$ \\
\hline
\end{tabular}

Note: This table provides a summary of the experimental design, with each treatment and action set in its own row. The total endowment (column 3) represents the amount to dictator and recipient at the beginning of the game (dictator's endowment is the first number; recipient's endowment is the second number. The variable endowment (column 2) is the amount originally allocated to each child that the dictator can reallocate.

Table 2: Summary Statistics (First Decision Only - Between Subjects)

\begin{tabular}{|l|l|l|l|l|l|}
\hline \multirow{5}{*}{ Inequality } & $\begin{array}{l}\text { Moral } \\
\text { Reference } \\
\text { Point } \\
\text { (Dictator, } \\
\text { Recipient) }\end{array}$ & $\begin{array}{l}\text { Transfer } \\
\text { Amount } \\
\text { (Send is } \\
\text { positive, Take } \\
\text { is negative) }\end{array}$ & $\begin{array}{l}\text { Final Payoffs } \\
\text { (Dictator, } \\
\text { Recipient) }\end{array}$ & N \\
& Give & $(6,4)$ & $1.49(1.14)$ & $(6.51,5.49)$ & 53 \\
\cline { 2 - 6 } & Take & $(4,4)$ & $-2.16(1.13)$ & $(6.16,5.84)$ & 51 \\
\cline { 2 - 6 } & Symmetric & $(6,0)$ & $-0.70(1.57)$ & $(8.70,3.29)$ & 64 \\
\hline \multirow{5}{*}{ Equal } & Give & $(4,6)$ & $0.94(1.29)$ & $(5.06,6.94)$ & 33 \\
\cline { 2 - 6 } & Take & $(2,6)$ & $-2.60(1.08)$ & $(4.60,7.40)$ & 25 \\
\cline { 2 - 6 } & Symmetric & $(4,2)$ & $-1.13(1.61)$ & $(7.13,4.87)$ & 30 \\
\hline \multirow{5}{*}{ Envy } & Give & $(2,8)$ & $0.62(1.12)$ & $(3.38,8.62)$ & 21 \\
\cline { 2 - 6 } & Take & $(0,8)$ & $-2.84(1.28)$ & $(2.84,9.16)$ & 25 \\
\cline { 2 - 6 } & Symmetric & $(2,4)$ & $-1.29(1.81)$ & $(5.29,6.71)$ & 31 \\
\hline
\end{tabular}

Note: Column 1 shows the average transfer rate, with standard deviation in parentheses. Column 2 shows the final payoffs, with dictator payoff first followed by recipient payoff. $N$ is the number of observations in each treatment. Only decisions made first in order are included. 
Table 3: Comparisons of Give vs. Take Action Sets Average marginal effects from the Hurdle model (Cragg, 1971).

\section{Dependent Variable}

Dictator Payoff Inequality Equal Envy

Conditional mean estimates of

$\begin{array}{llcc}\text { Give Action }[+] & 0.400^{*} & 0.246 & 1.174 * * \\ & (0.216) & (0.326) & (0.458)\end{array}$

\begin{tabular}{|c|c|c|c|}
\hline Observations & 103 & $57^{\mathrm{a}}$ & 46 \\
\hline Means $\{$ Take, Give $\}$ & $\{6.16,6.51\}$ & $\{4.60,5.06\}$ & $\{2.84,3.38\}$ \\
\hline Nobs $\{$ Take, Give $\}$ & $\{50,53\}$ & $\{25,33\}$ & $\{25,21\}$ \\
\hline (Kruskal-Wallis) Chi-Squared & 2.51 & $3.26^{*}$ & $2.88 *$ \\
\hline $\begin{array}{l}\text { Note: }{ }^{\mathrm{a}} \text { Demographics missing } \\
\text { orackets. Standard errors in par } \\
\text { as hurdle. Includes Experimenter } \\
\text { Take action set is the omitted c } \\
\text { are excluded from the analysis. * }\end{array}$ & $\begin{array}{l}\text { child. P } \\
\text { Choice at } \\
\text { ects and der } \\
\text { nd children } \\
* * \mathrm{p}<0.05 \text {, }\end{array}$ & $\begin{array}{l}\text { ted sign b } \\
\text { ighest dictat } \\
\text { aphics (child } \\
\text { oices in the } \\
\text {.1 }\end{array}$ & $\begin{array}{l}\text { MA in square } \\
\text { ayoff is treated } \\
\text { ace and gender). } \\
\text { metric action set }\end{array}$ \\
\hline
\end{tabular}


Table 4: Contraction of the Symmetric Set (within treatment)

Average marginal effects from the hurdle model (Cragg, 1971).

\begin{tabular}{|c|c|c|c|}
\hline $\begin{array}{l}\text { Dependent Variable } \\
\text { Dictator Payoff }\end{array}$ & $\begin{array}{c}\text { (1) } \\
\text { Inequality }\end{array}$ & $\begin{array}{c}(2) \\
\text { Equal }\end{array}$ & $\begin{array}{c}\text { (3) } \\
\text { Envy }\end{array}$ \\
\hline Give Action [-] & $\begin{array}{c}-0.930 * * * \\
(0.263)\end{array}$ & $\begin{array}{c}-1.585^{* * *} \\
(0.532)\end{array}$ & $\begin{array}{l}-0.570 \\
(0.482)\end{array}$ \\
\hline Take Action [-] & $\begin{array}{c}-1.293 * * * \\
(0.245)\end{array}$ & $\begin{array}{c}-1.782 * * * \\
(0.522)\end{array}$ & $\begin{array}{c}-1.477 * * * \\
(0.440)\end{array}$ \\
\hline Observations & $143^{\mathrm{a}}$ & $73^{\mathrm{a}}$ & 64 \\
\hline Means (Take, Give, Symm.) & $(6.16,6.51,7.83)$ & $(4.60,5.06,5.94)$ & $(2.84,3.38,3.94)$ \\
\hline Nobs (Take, Give, Symm.) & $(50,53,41)$ & $(25,33,16)$ & $(25,21,18)$ \\
\hline $\begin{array}{l}\text { (Kruskal-Wallis test) } \\
\text { Chi-Squared }\end{array}$ & $52.07 * * *$ & $15.51 * * *$ & $12.25 * * *$ \\
\hline $\begin{array}{l}\text { Note: }{ }^{\text {aDemographics missir }} \\
\text { Standard errors in parenthes } \\
\text { (gender, age, race). The Symn } \\
\text { are included. Choice at the hig } \\
\mathrm{p}<0.1 \text {. }\end{array}$ & $\begin{array}{l}\text { or one child. } \\
\text { Includes Experim } \\
\text { c action set is the } \\
\text { dictator's payoff }\end{array}$ & $\begin{array}{l}\text { A predicted sign } \\
\text { r fixed effects and } \\
\text { hitted category. Only } \\
\text { eated as hurdle. *** }\end{array}$ & $\begin{array}{l}\text { in square brackets } \\
\text { hildren demographics } \\
\text { choices from [A, B] } \\
\mathrm{p}<0.01,{ }^{* *} \mathrm{p}<0.05, *\end{array}$ \\
\hline
\end{tabular}


Table 5: Contraction of the Symmetric Set (across treatments)

Average marginal effects from the hurdle model (Cragg, 1971).

\begin{tabular}{lcc}
\hline $\begin{array}{l}\text { Dependent Variable } \\
\text { Dictator Payoff }\end{array}$ & $\begin{array}{c}(1) \\
\text { Symmetric Equal } \\
\text { Inequality Take/Give }\end{array}$ & $\begin{array}{c}(2) \\
\text { Symmetric Envy } \\
\text { Inequality Take/Give }\end{array}$ \\
\hline Give Action & 0.082 & $1.301^{* * *}[+]$ \\
Take Action & $(0.277)$ & $(0.296)$ \\
& $-0.286[-]$ & $0.875^{* * *}[+]$ \\
Observations & $(0.289)$ & $(0.320)$ \\
\hline Means (Take, Give, Symm.) & $(6.16,6.51,6.42)$ & $(6.16,6.51,5.37)$ \\
Nobs (Take, Give, Symm.) & $(50,53,24)$ & $(50,53,30)$ \\
\hline (Kruskal-Wallis test) & 2.81 & $11.67^{* * *}$ \\
Chi-Squared & & \\
\end{tabular}

Note: MMA predicted sign in square brackets. Standard errors in parentheses. Includes Experimenter fixed effects and children demographics (gender, age, race). The Symmetric action set is the omitted category and only choices from the contraction set are included. Choice at the highest dictator's payoff is treated as hurdle. ${ }^{* * *} \mathrm{p}<0.01,{ }^{* *} \mathrm{p}<0.05,{ }^{*} \mathrm{p}<0.1$. 


\section{FIGURES}

\section{Figure 1: Feasible Sets (AB for Give or Take, AC for Symmetric)}
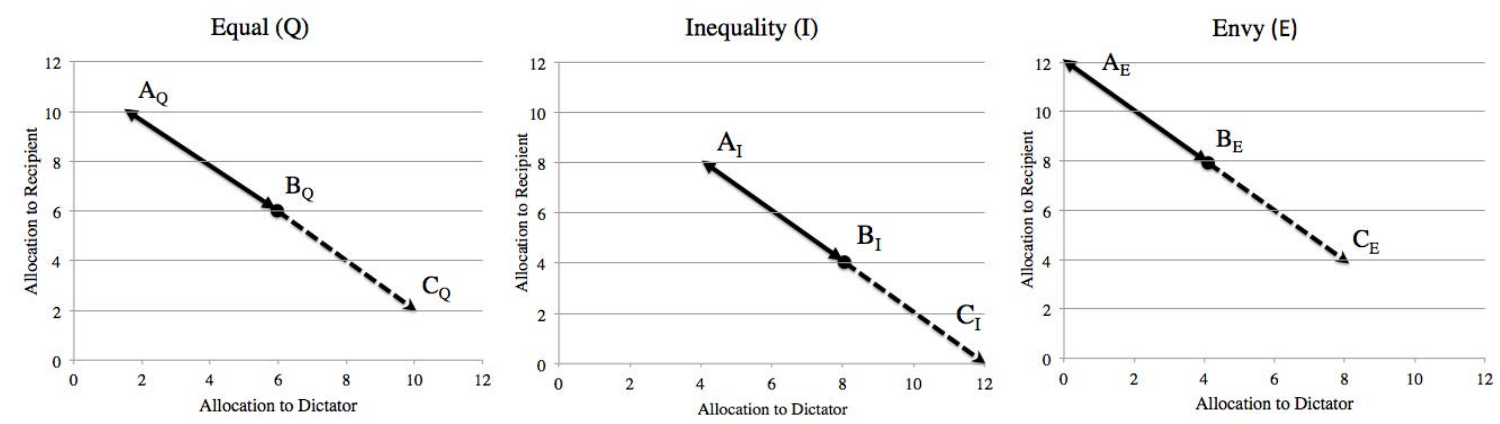

Note: This figure shows the feasible budget available for each treatment and action set. Participants in the Give or Take action sets can choose from [A, B], while participants in the Symmetric action set can choose from $[A, C]$.

\section{Figure 2: Experimental Setup}
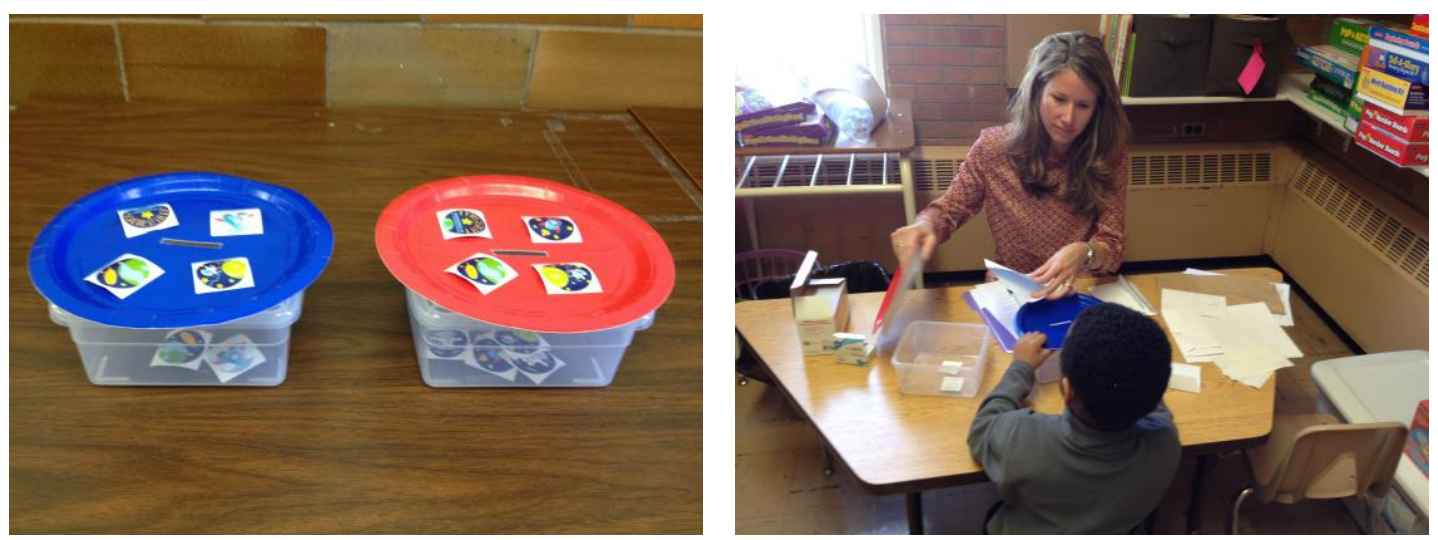

Note: This figure displays the experimental environment. At left, blue and red plates indicate payoffs for the dictator and recipient. Stickers on top of the plate are variable endowment, while clearly visible stickers inside the boxes are fixed endowment. At right, a child participates in the experiment one on one with an experimenter. 
Figure 3: Histograms using Data from List (2007) and Bardsley (2008)
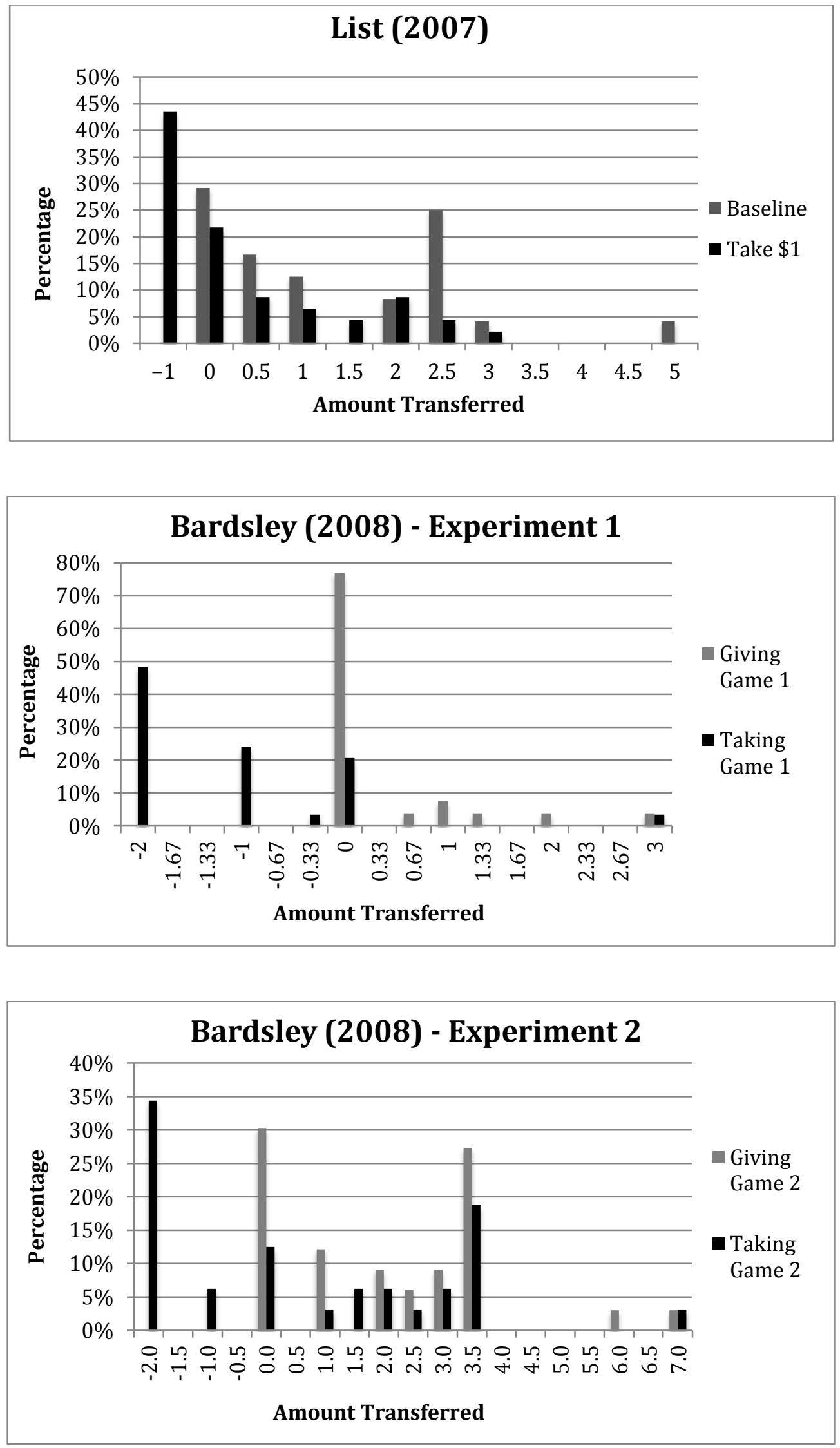
Figure 4: Example of Choice with non-Convex Preferences

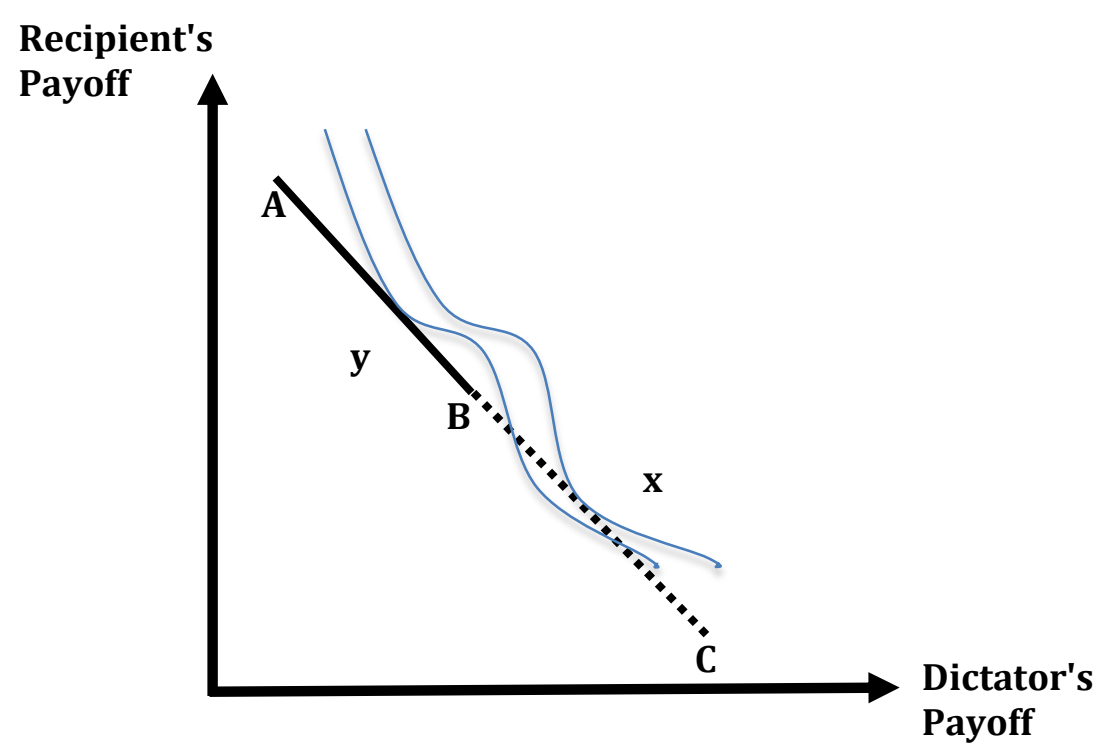

Figure 5: Reference Points for Proper Contraction Sets

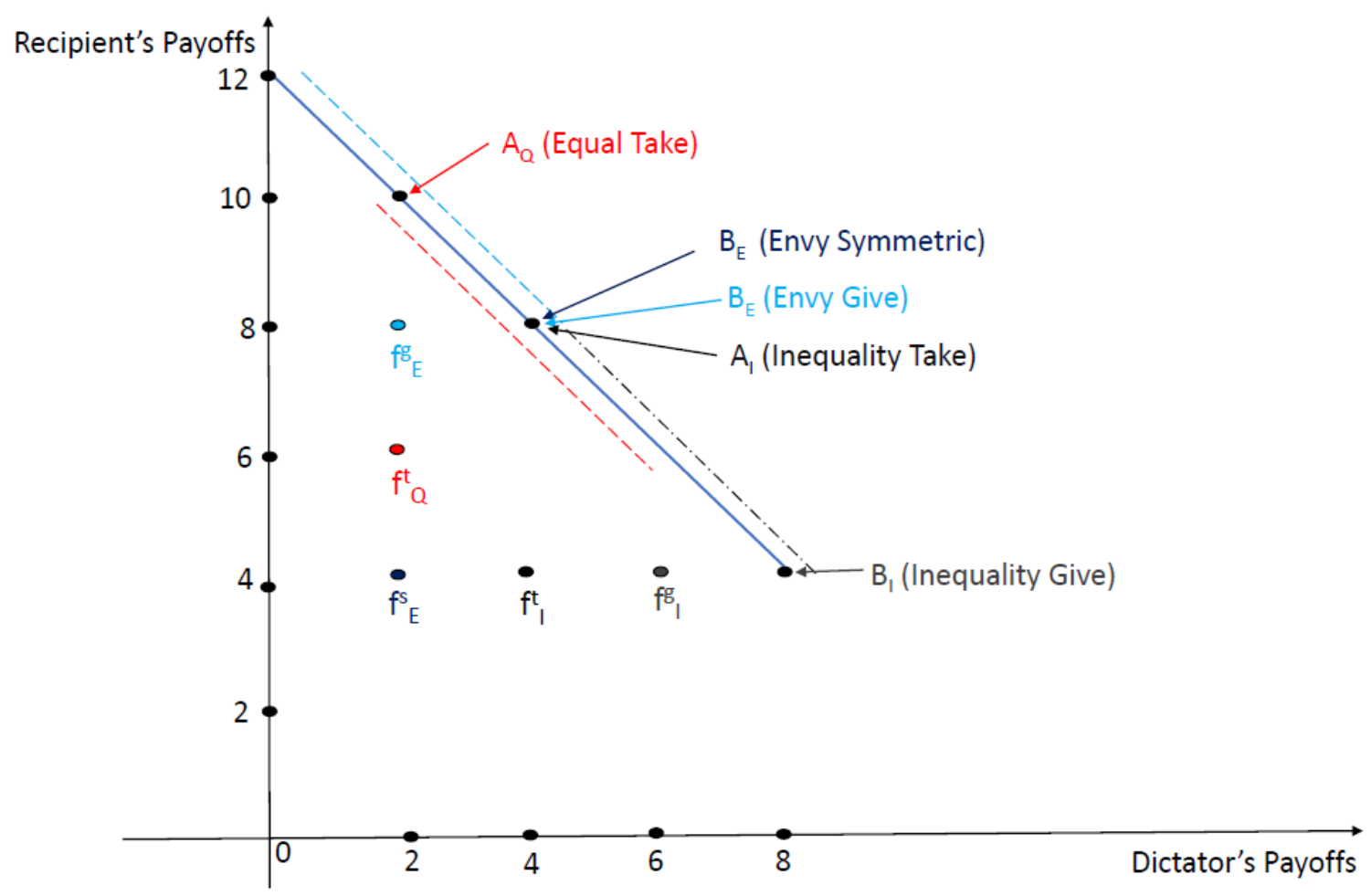


Figure 6: Histograms of Final Payoff to Dictator in the Experiment
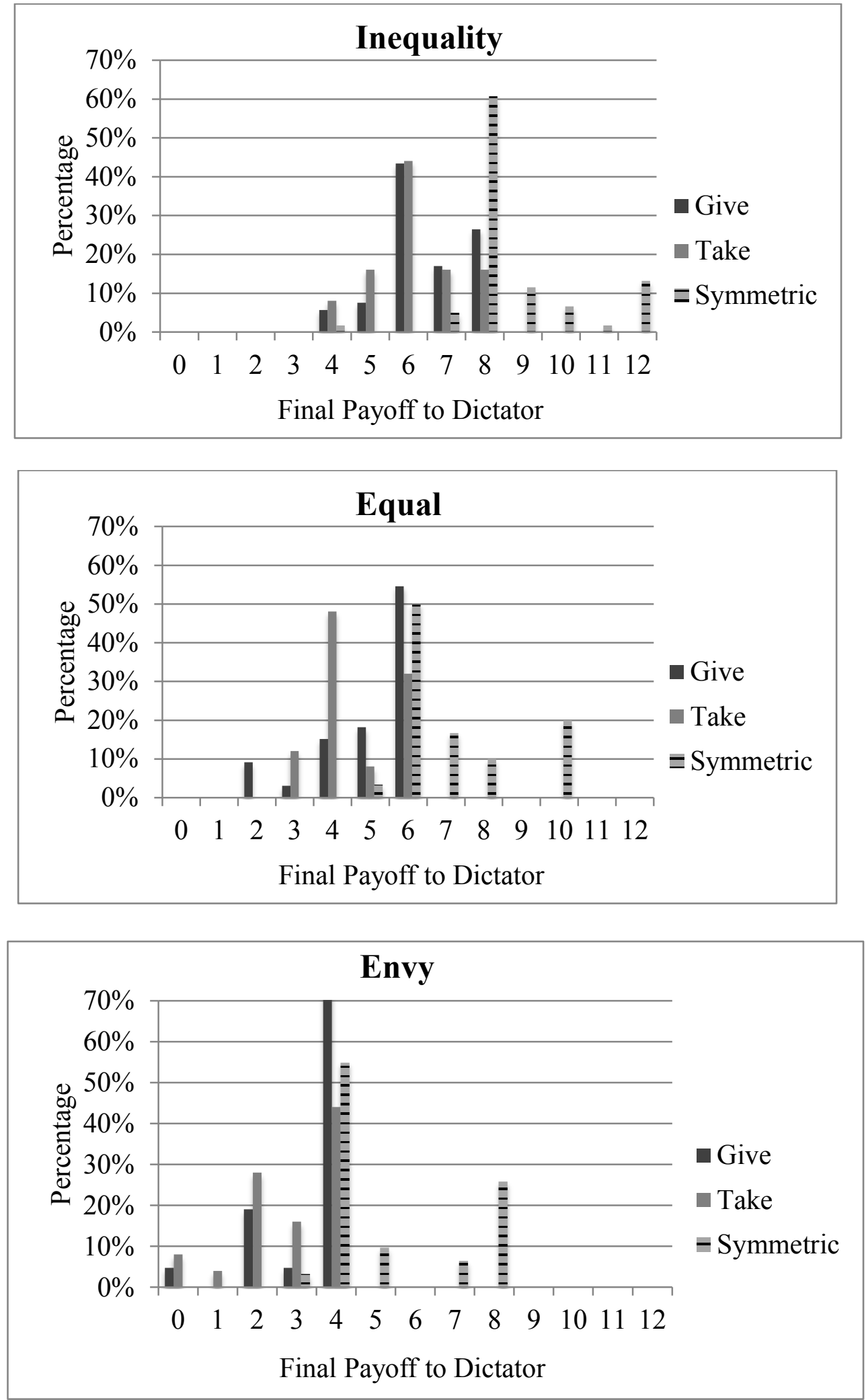
Figure 7. MMA Implies WARP for the Andreoni and Miller Experiment

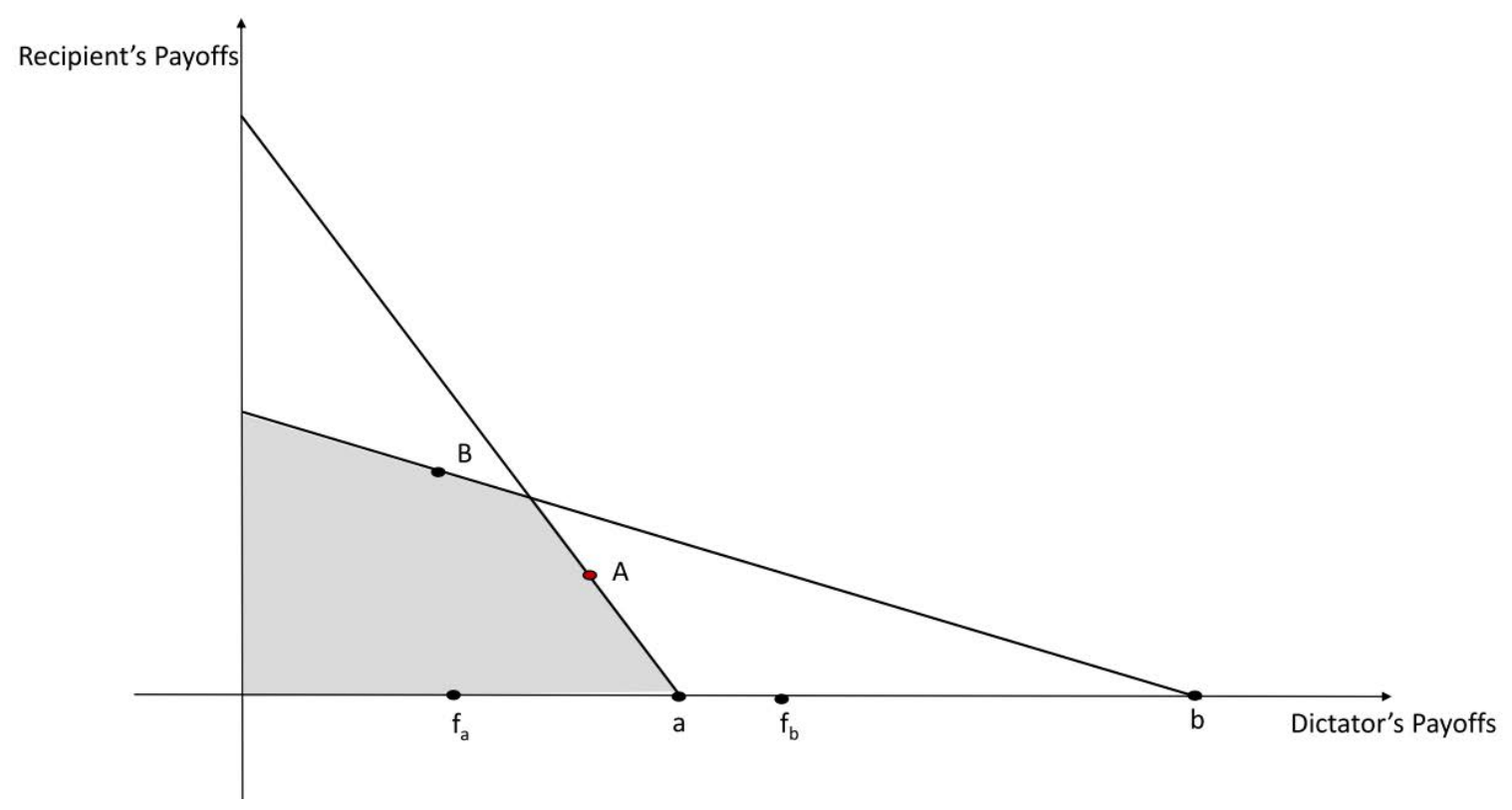

Figure 8: Endowments and Moral Reference Points for Korenok, et al. Treatments

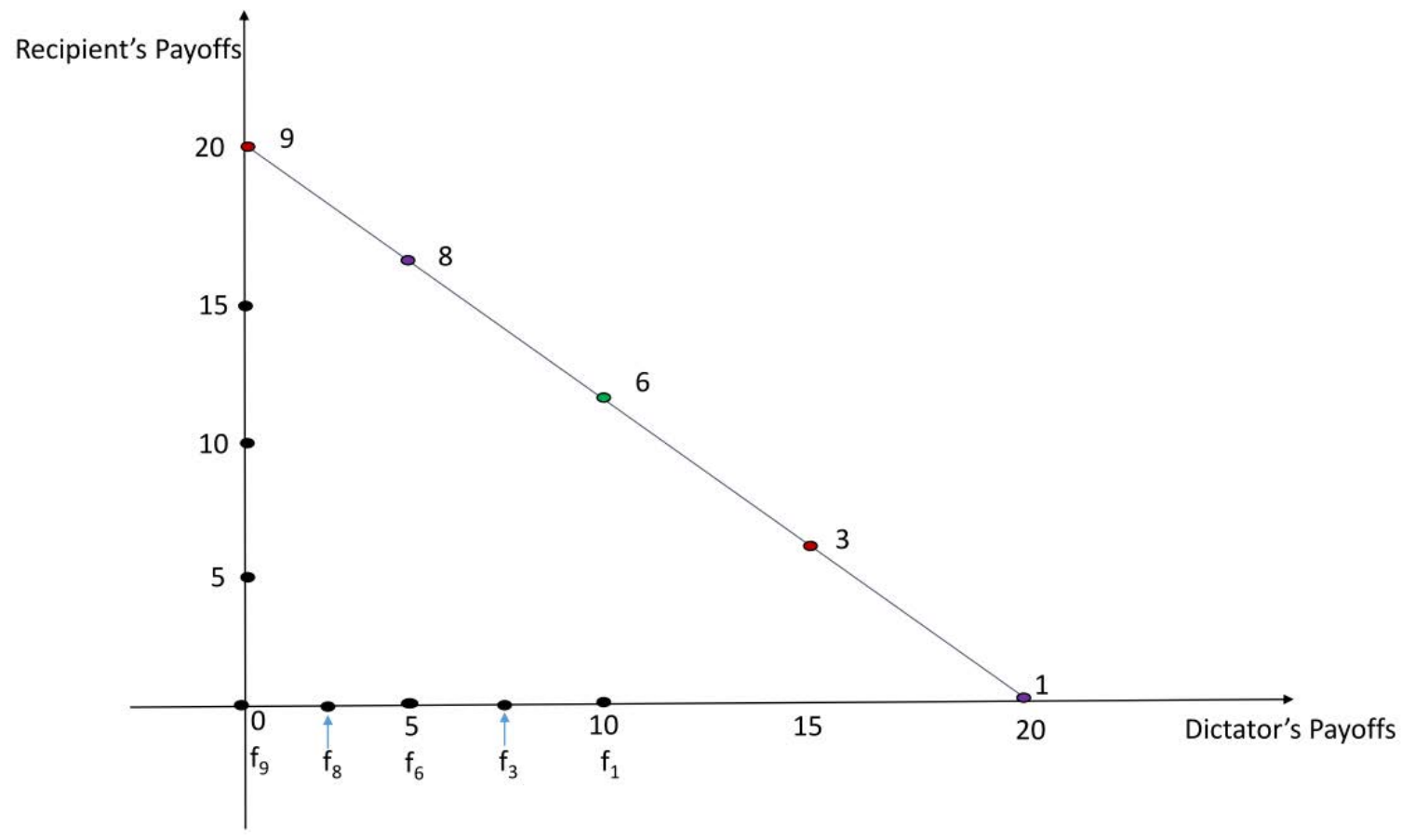




\section{APPENDICES}

\section{A. Proof of Proposition 1}

Let $f$ belong to both $F^{*}$ and $G$. Consider any $g$ from $G^{*}$. As $\mathrm{G}$ and $\mathrm{F}$ have the same moral reference point, $g^{r}=f^{r}$, MMA requires that $g_{i} \geq f_{i}$ and $g_{i} \leq f_{i}, \forall i$. These inequalities can be simultaneously satisfied if and only if $g \equiv f$, i.e. $f$ belongs to $G^{*}$ which concludes the proof for property $\alpha_{M}$. Note, though, that any choice $g$ in $G^{*}$ must coincide with $f$, an implication of which is $G^{*}$ must be a singleton. So, if the intersection of $F^{*}$ and $G$ is not empty then choices satisfy property $\beta_{M}$.

\section{B. Chicago Heights Early Childhood Center (CHECC) Laboratory}

The studies were conducted at the Chicago Heights Early Childhood Center (CHECC) in the winter of 2013 (CHECC was formerly named GECC, the Griffin Early Childhood Center). The CHECC program was launched in 2010 and serves as a 'laboratory' for experiments of this sort. The CHECC program is located in Chicago Heights, Illinois and interested families can sign up via lottery to participate in one of the offered programs each year. The CHECC itself is a randomized field experiment testing the effects of different early childhood intervention programs for 3-5 year old children. Chicago Heights, IL is a predominately low-income area, with a median annual income of $\sim \$ 43,000$. Children know others from their own classroom, but generally do not interact with children from other classrooms. For this experiment, we recruited families from all cohorts who have participated in the CHECC pool between 2010 and 2013.

Families with children Families from all CHECC cohorts were invited to participate in this experiment via mail and phone calls. When participants are recruited into CHECC, the optional activities that are part of the program are explained. Participants did not know what the activity was about when they signed up. Parents were told that they would receive $\$ 10$ just for coming, and that their child would have the chance to earn more prizes, for a "Child Activity" that would take around 15-20 minutes of their time. Some parents and children had previously participated in activities that are unrelated to this project. Children currently in a full-day preschool program at CHECC participated by being taken out of class.

We followed a standard procedure developed at GECC to conduct the study. Experiments involving children at CHECC are conducted one-on-one with the experimenter. Thus, in a sense there were separate individual sessions of the experiment. One of the authors was in charge of implementing the study, including training staff, monitoring recruitment, observing the staff during the duration of the experiment, and monitoring data entry. We used several different experimenters, who were all Research Assistants or full time staff at the University of Chicago working for the authors and have experience in conducting other experiments at CHECC. The experiment was conducted in Spanish for the Spanishspeaking children. The remaining experiments were conducted in English. The study also required the use of several waiting area assistants and babysitters, and check-in staff, who were also Research Assistants at the university or interns at the CHECC. 


\section{Appendix C: Script and Instructions for the Experiment}

The below provides the script read by the experimenter for the Inequality treatment, including Give, Take and Symmetric action sets. The Equal and Envy treatments were the same, and only differed in the number of stickers available initially. Note we always paired girls with girls and boys with boys, since it is difficult to explain to a child that they are playing with a recipient of an unknown gender, and since we did not want to add another variable to the data in terms of same or mis-matched gender of the dictator and recipient. This is a common procedure in developmental psychology studies.

\section{Inequality Treatment - Give Action}

Do you want to play some games? (Remember to match gender)

Ok, first we get to decide which stickers to play with. Here are your choices; you can pick one sticker set - which one is your favorite? Great let's get started. (record)

\section{$\begin{array}{lll}\text { Choice: } & \text { STAR } & \text { MUSTACHE }\end{array}$}

$\mathrm{OK}$, in this game, you are going to be matched with another girl who is from a different school and did not get to play the game today. You will each get some stickers, and it will be up to you to decide how many you keep, and how many we send to the other girl, ok? We'll send the stickers in the mail, so she won't know who you are, and you won't know who she is either.

First, you and the other girl will get some stickers to start with. This is going to be your box and your plate (point) and this is going to be the other girl's box and her plate (point).

Here are some instructions that tell me what to put in each box and plate (look over instruction). Ok -

I'm going to put your stickers in your box (place 4 stickers in box) and I'm going to put the other girl's stickers in her box (place 4 stickers in box). These are the stickers you definitely get to take home (point to the child's box), and these are the stickers the other girl will definitely get (point to the other child's box).

- Can you show me which stickers you definitely get to keep? (that's right / no, actually. you definitely gets the ones in your box here)

- Can you show me which stickers the other girl definitely gets to keep? (that's right / no, actually she definitely gets the ones in her box here)

Now here are more stickers - they are yours now (put 4 stickers in child's plate). With the stickers on the plate, you still get to decide -- how many you want to keep, and how many you want to send to the other girl for her to have. You can do whatever you want, it is up to you. You can keep as many stickers as you want, and you can send none, some or all of your stickers to the other girl.

Any stickers you are going to keep, you will leave them on your plate (point) Any stickers you want to send to the other girl, you put them on the other girl's plate here (point). We'll add the stickers on your plate to your box, and we'll add the stickers on the other girl's plate to her box.

- Can you show me which plate is your plate? (that's right, this is your plate. / no, actually this one is your plate. You take home the stickers on this plate)

- Can you show me which plate is the other girl's plate? (that's right, this is the other girl's plate / no, actually this one is the other girl's plate. She takes home the stickers on this plate)

Ok, go ahead and decide where the stickers will go, on your plate or the other girl's plate. Remember, it is up to you! When you're ALL DONE you can drop the stickers in the boxes! 
Great, now I am going to put your stickers in your envelope for you to take home and the other stickers in the other girl's envelope to send to her. Record how many stickers are on each plate.

\section{Inequality Treatment - Take Action}

Do you want to play some games? (Remember to match gender)

Ok, first we get to decide which stickers to play with. Here are your choices; you can pick one sticker set - which one is your favorite? Great let's get started. (record)

\section{$\begin{array}{lll}\text { Choice: } & \text { STAR }\end{array}$}

OK, in this game, you are going to be matched with a different girl who is from a different school and did not get to play the game today. You will each get some stickers, and it will be up to you to decide how many you keep, and how many we send to the other girl, ok? We'll send the stickers in the mail, so she won't know who you are, and you won't know who she is either.

First, you and the other girl will get some stickers to start with. This is going to be your box and your plate (point) and this is going to be the other girl's box and her plate (point).

Here are some instructions that tell me what to put in each box and plate (look over instruction). Ok -

I'm going to put your stickers in your box (place 4 stickers in box) and I'm going to put the other girl's stickers in her box (place 4 stickers in box). These are the stickers you definitely get to take home (point to the child's box), and these are the stickers the other girl will definitely get (point to the other child's box).

- Can you show me which stickers you definitely get to keep? (that's right / no, actually. you definitely gets the ones in your box here)

- Can you show me which stickers the other girl definitely gets to keep? (that's right / no, actually she definitely gets the ones in her box here)

Now here are more stickers - they are the other girl's now (put 4 stickers in other child's plate). With the stickers on her plate, you still get to decide -- how many you want the other girl to keep, and how many you want to take from the other girl for you to keep. You can do whatever you want, it is up to you. You can take as many stickers as you want - you can take none, some or all of the other girl's stickers.

Any stickers you are going to take for yourself, you will put them on your plate (point) Any stickers you want to leave for the other girl, you leave them on the other girl's plate here (point).We'll add the stickers on your plate to your box, and we'll add the stickers on the other girl's plate to her box.

- Can you show me which plate is your plate? (that's right, this is your plate. / no, actually this one is your plate. You take home the stickers on this plate)

- Can you show me which plate is the other girl's plate? (that's right, this is the other girl's plate / no, actually this one is the other girl's plate. She takes home the stickers on this plate)

Ok, go ahead and decide where the stickers will go, on your plate or the other girl's plate. Remember, it is up to you! When you're ALL DONE you can drop the stickers in the boxes!

Great, now I am going to put your stickers in your envelope for you to take home and the other stickers in the other girl's envelope to send to her. Record how many stickers are on each plate

\section{Inequality Treatment - Symmetric Action}

Do you want to play some games? (Remember to match gender) 
Ok, first we get to decide which stickers to play with. Here are your choices; you can pick one sticker set - which one is your favorite? Great let's get started.

$\begin{array}{lll}\text { Choice: } & \text { STAR }\end{array}$

$\mathrm{OK}$, in this game, you are going to be matched with another girl who is from a different school and did not get to play the game today. You will each get some stickers, and it will be up to you to decide how many you keep, and how many we send to the other girl, ok? We'll send the stickers in the mail, so she won't know who you are, and you won't know who she is either.

First, you and the other girl will get some stickers to start with. This is going to be your box and your plate (point) and this is going to be the other girl's box and her plate (point).

Here are some instructions that tell me what to put in each box and plate (look over instruction). Ok -

I'm going to put your stickers in your box (place 4 stickers in box) and not going to put any stickers in her box (place $\mathbf{0}$ stickers in box). These are the stickers you definitely get to take home (point to the child's box).

- Can you show me which stickers you definitely get to keep? (that's right / no, actually. you definitely gets the ones in your box here)

- Can you show me which box is her box? (that's right / no, actually this is your box)

Now here are more stickers - they are yours now (put 4 stickers in child's plate). And here are even more stickers - they are the other girl's now (put 4 stickers on other child's plate). With the stickers on both of these plates, you still get to decide -- how many you want to keep, and how many you want the other girl to keep. You can do whatever you want, it is up to you. You can send stickers from your plate to the other girl, and you can take stickers from the other girl's plate to put on your plate. You can send none, some or all of the stickers from your plate to the other girl. You can also take none, some or all of the stickers from the other girl.

Any stickers you are going to keep, you will put them on your plate (point) Any stickers you want the other girl to keep, you put them on the other girl's plate here (point). We'll add the stickers on your plate to your box, and we'll add the stickers on the other girl's plate to her box.

- Can you show me which plate is your plate? (that's right, this is your plate. / no, actually this one is your plate. You take home the stickers on this plate)

- Can you show me which plate is the other girl's plate? (that's right, this is the other girl's plate / no, actually this one is the other girl's plate. She takes home the stickers on this plate)

Ok, go ahead and decide where the stickers will go, on your plate or the other girl's plate. Remember, it is up to you! When you're ALL DONE you can drop the stickers in the boxes!

Great, now I am going to put your stickers in your envelope for you to take home and the other stickers in the other girl's envelope to send to her. Record how many stickers are on each plate 


\section{Appendix D. Empirical Analysis Using Data for all Three Choices}

Table D.3: Comparisons of Give vs. Take Action Sets

Average marginal effects from the Hurdle model (Cragg, 1971).

\begin{tabular}{|c|c|c|c|}
\hline Dependent Variable & (1) & (2) & (3) \\
\hline Dictator Payoff & Inequality & Equal & Envy \\
\hline \multicolumn{4}{|l|}{ Conditional mean estimates of } \\
\hline Give Action $[+]$ & $\begin{array}{l}0.243^{\star *} \\
(0.113)\end{array}$ & $\begin{array}{c}0.504^{\star * *} \\
(0.189)\end{array}$ & $\begin{array}{c}0.494^{\star \star \star} \\
(0.186)\end{array}$ \\
\hline Observations & $326^{\mathrm{a}}$ & $173^{\mathrm{a}}$ & 154 \\
\hline Means $\{$ Take, Give $\}$ & $\{6.42,6.67\}$ & $\{4.5,5.03\}$ & $\{2.81,3.40\}$ \\
\hline Nobs $\{$ Take, Give $\}$ & $\{164,164\}$ & $\{88,88\}$ & $\{77,77\}$ \\
\hline (Subject ID Paired) t-test & $2.095 * *$ & $2.672 * * *$ & $2.931 * * *$ \\
\hline \multicolumn{4}{|c|}{$\begin{array}{l}\text { Note: }{ }^{a} \text { Missing demographics for one child. Predicted sign by MMA in square brackets. } \\
\text { Standard errors in parentheses and clustered at children ID level. Choice at the highest } \\
\text { dictator's payoff is treated as hurdle. Includes Experimenter fixed effects and demographics } \\
\text { (child age, race and gender). Take action set is the omitted category, and children choices in } \\
\text { the Symmetric action set are excluded from the analysis. }{ }^{* *} \mathrm{p}<0.01, * * \mathrm{p}<0.05, * \mathrm{p}<0.1\end{array}$} \\
\hline
\end{tabular}




\section{Table D4: Contraction of the Symmetric Set (within treatment)}

Average marginal effects from the hurdle model (Cragg, 1971).

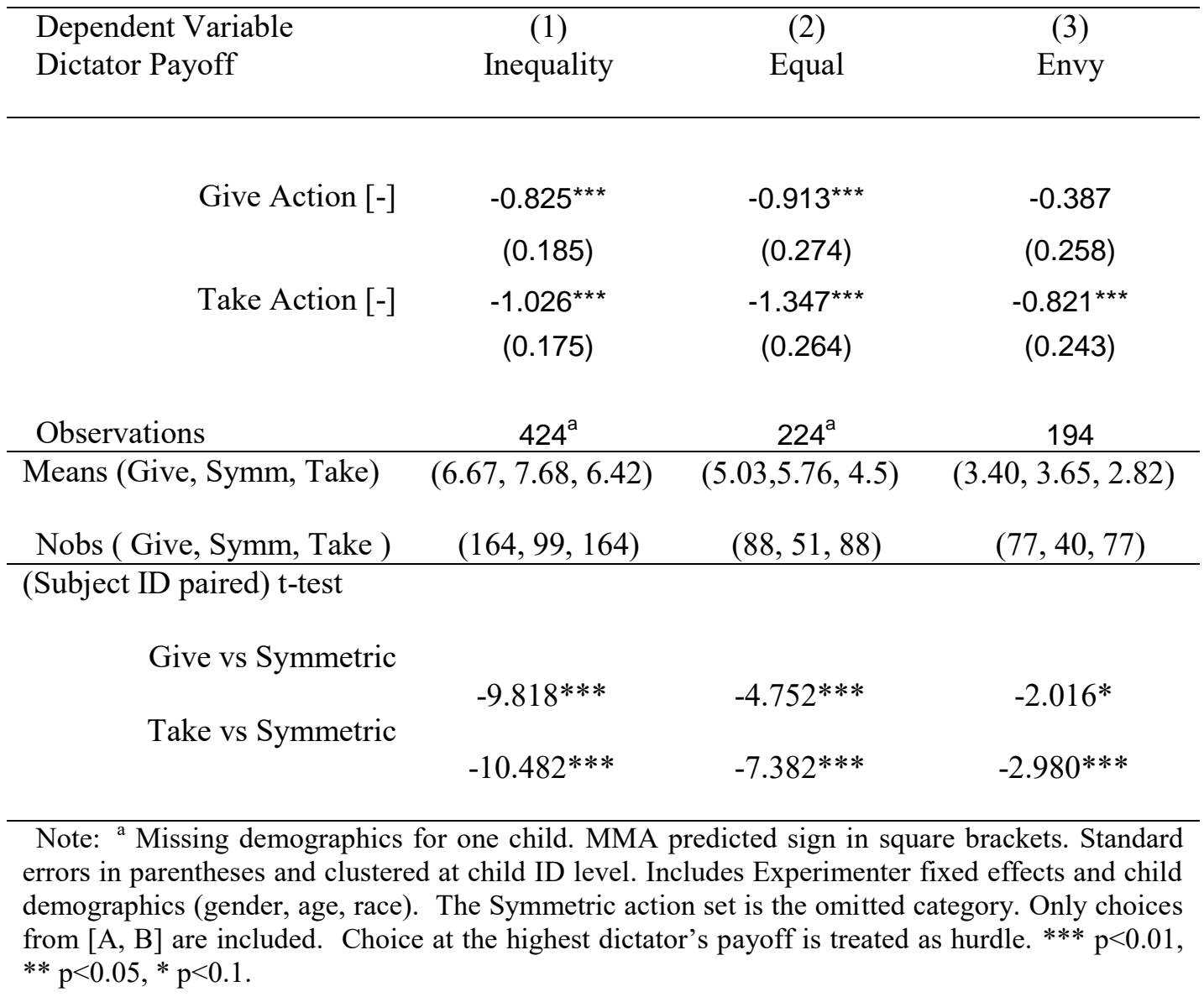


Table D5: Contraction of the Symmetric Set (across treatments) ${ }^{26}$ Average marginal effects from the hurdle model (Cragg, 1971).

\begin{tabular}{|c|c|c|}
\hline $\begin{array}{l}\text { Dependent Variable } \\
\text { Dictator Payoff }\end{array}$ & $\begin{array}{c}\text { (1) } \\
\text { Symmetric Equal } \\
\text { Inequality Take/Give }\end{array}$ & $\begin{array}{c}\text { (2) } \\
\text { Symmetric Envy } \\
\text { Inequality Take/Give }\end{array}$ \\
\hline Give Action & $\begin{array}{l}0.488^{* * *} \\
(0.163)\end{array}$ & $\begin{array}{c}1.188^{* * *}[+] \\
(0.197)\end{array}$ \\
\hline Take Action & $\begin{array}{c}0.255[-] \\
(0.170)\end{array}$ & $\begin{array}{l}0.942^{\star * *}[+] \\
\quad(0.200)\end{array}$ \\
\hline Observations & $398^{\mathrm{a}}$ & 397 \\
\hline Means (Give, Take, Symm) & $(6.67,6.42,6.33)$ & $(6.67,6.42,5.59)$ \\
\hline Nobs ( Give, Take, Symm) & $(164,164,73)$ & $(164,164,71)$ \\
\hline $\begin{array}{l}\text { Note: }{ }^{\text {a }} \text { Missing demographics } \\
\text { Standard errors in parentheses } \\
\text { fixed effects and children demo } \\
\text { the omitted category and only c } \\
\text { highest dictator's payoff is treat }\end{array}$ & $\begin{array}{l}\text { one child. MMA predic } \\
\text { clustered at childrenID } \\
\text { hics (gender, age, race). } \\
\text { es from the contraction s } \\
\text { hurdle. } * * * p<0.01, * * p\end{array}$ & $\begin{array}{l}\text { sign in square brackets. } \\
\text { 1. Includes Experimenter } \\
\text { Symmetric action set is } \\
\text { e included. Choice at the } \\
5, * p<0.1 \text {. }\end{array}$ \\
\hline
\end{tabular}

\footnotetext{
${ }^{26} \mathrm{We}$ cannot conduct (subject ID) paired t-test here as no child participated in different treatments.
} 